\title{
Mediating functions and the semantics of noun incorporation
}

\author{
Andrew McKenzie ${ }^{1}$
}

Received: 9 January 2018 / Accepted: 6 March 2021 / Published online: 9 April 2021

(C) The Author(s) 2021

\begin{abstract}
Noun incorporation is commonly thought to avoid the weak compositionality of compounds because it involves conjunction of an argument noun with the incorporating verb. However, it is weakly compositional in two ways. First, the noun's entity argument needs to be bound or saturated, but previous accounts fail to adequately ensure that it is. Second, non-arguments are often incorporated in many languages, and their thematic role is available for contextual selection.

We show that these two weaknesses are actually linked. We focus on the Kiowa language, which generally bars objects from incorporation but allows non-arguments. We show that a mediating relation is required to semantically link the noun to the verb. Absent a relation, the noun's entity argument is not saturated, and the entire expression is uninterpretable. The mediating relation for non-objects also assigns it a thematic role instead of a postposition. Speakers can choose this role freely, subject to independent constraints from the pragmatics, syntax, and semantics.

Objects in Kiowa are in fact allowed to incorporate in certain environments, but we show that these all independently involve a mediating relation. The mediating relation for objects quantifies over the noun and links the noun+verb construction to the rest of the clause. The head that introduces this relation re-categorizes the verb in the syntactic derivation. Essentially, we demonstrate two distinct mechanisms for noun incorporation.

Having derived the distribution of Kiowa, we apply the same relations to derive constraints on English complex verbs and synthetic compounds, which exhibit most of the same constraints as Kiowa noun incorporation. We also look at languages with routine object incorporation, and show how the transitivity of the verb depends on whether the $v^{\circ}$ head introducing the external argument assigns case to the recategorized verb.
\end{abstract}

A. McKenzie

andrew.mckenzie@ku.edu

1 University of Kansas, Lawrence, KS, USA 
Keywords Incorporation · Compositionality · Synthetic compounds ·

Quantification · Intensionality · Kiowa

\section{Introduction}

This paper brings together two issues in the semantics of word-building to argue that mediating relations are present in the interpretation of many incorporation structures. Compounds are renowned for their "weak compositionality" (Pirrelli 2002), because the link between the combining parts involves material left to the context; for instance, compare sundress 'a dress to be worn when the sun is out' with sunflower 'a flower that resembles the sun' or suntan 'a skin tinting caused by the sun's radiation'. Noun incorporation is commonly held to be distinct from compounds in that sense, because it generally involves the straightforward composition of an argument noun to an incorporating verb, like the West Greenlandic timmisartu+liur- [airplane+make-] 'make an airplane' (Van Geenhoven 1998).

However, we know that noun-incorporating structures can also show weak compositionality in a number of languages. In some cases, an incorporated noun is linked to the event by a thematic role available through contextual selection. For instance, the incorporated noun in the Nahuatl expression kočillo+tete'ki [knife+cut] is the instrument of the described event (Baker 1988:79).

We even know of non-compositionality in incorporation and pseudo-incorporation. Mithun (1984:866) offers numerous examples of idiomatic expressions, like Gunwinggu's verb wog-benmigda [word+forget] 'to disobey'. Dayal (2011:133) notes that Hindi laRkii+dekhnaa [girl+seeing] is limited in meaning to finding a bride, and makkhii+maarnaa [fly+kill] means 'waste time'. However, we will maintain idioms as non-compositional, distinct from weakly compositional cases where the components transparently contribute to part of the meaning, and focus on the latter.

The inquiry of this paper will begin with the observation that even apparently simple object incorporation is weakly compositional, because the noun's entity argument is not saturated by any noticeably overt morpheme or available functional head. Previous accounts of the semantics of incorporation (and pseudo-incorporation) have addressed this issue in various ways (Van Geenhoven 1998; Chung and Ladusaw 2006; Farkas and de Swart 2003; Dayal 2011). These accounts share a common core of conjunction and existential quantification, but differ regarding the source of these core elements.

Moreover, these accounts are based mainly or solely on cases and languages where objects are incorporated. In this paper we shift that basis to Kiowa, a language that allows many types of noun incorporation, but generally bars objects. We will zero in on the systematic semantic environments that do permit object incorporation. In doing so, we will demonstrate that 'weak compositionality' of noun incorporation and the availability of object incorporation are crucially linked. Both require the presence of a mediating relation that saturates the noun's entity argument. Absent a relation, this argument is not saturated, and the entire expression is uninterpretable. Mediating relations also fill the gaps that create an impression of weak compositionality, permitting productive incorporation of non-objects. 
We will bolster this case by showing how it applies to English, which is unrelated to Kiowa. English complex verbs exhibit the same restrictions that Kiowa noun incorporation exhibits, generally barring objects $\left({ }^{*} m e a t+c u t\right)$ unless lexicalization is involved (meat+cutter), while generally allowing non-objects (hand+cut). Ultimately, we show that objects and non-objects are incorporated by distinct processes, which result in different resolutions of weak compositionality.

\section{Weak compositionality in object incorporation}

Noun incorporation is the combination of a nominal stem with a verbal stem to which it is thematically related. For example, in (1), from West Greenlandic, the object noun timmisartu 'airplane' is combined into a complex word with the verb liur 'make'. ${ }^{1}$

(1) West Greenlandic

Suluut timmisartu+liur-puq.

S.ABS airplane+make-IND:INTR:3S

'Suulut made an airplane.'

(Van Geenhoven 1998:99)

Accounting for noun incorporation has required continuous revisiting of our understanding of argument structure, word building, and spell-out (Sadock 1980; Mithun 1984; Baker 1988; Rosen 1989; Baker 1996; Harley 2011; Compton and Pittman 2010:inter alia). It has also inspired us to question the semantics of how verbal meaning is built, because it requires a verbal mechanism to fully interpret the noun.

In the semantics, we find that incorporated nouns have similar properties in language after language. They must generally bear obligatory low scope, be numberneutral, and often have effects on valence. These properties are fairly easy to obtain since nouns denote properties. As a property, though, the noun's individual argument still requires saturation, and there the picture becomes more complicated.

In her seminal book, Van Geenhoven (1998) proposes a process called Semantic Incorporation, by which the noun's argument is bound by an operator in the verb (2). The verb takes the noun's property as its argument in the semantics. It binds the noun's argument, forcing low scope. Since the noun denotes a property, it is compatible with singular or non-singular meanings.

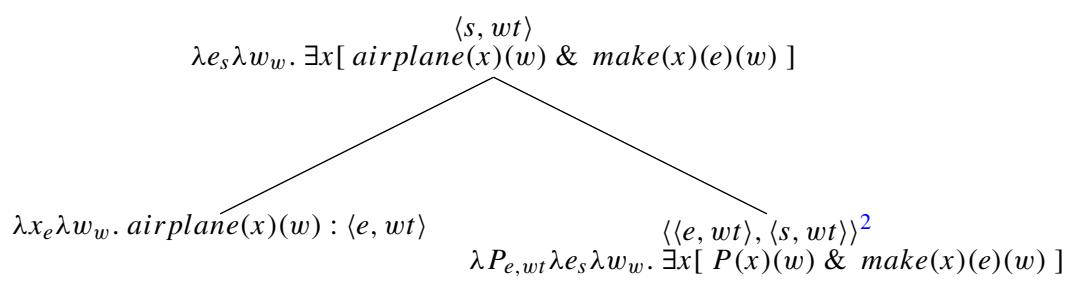

\footnotetext{
${ }^{1}$ Abbreviations follow Leipizig glossing conventions, with a few exceptions. Person: 1,2,3, Number: S,D,P; D: dative/oblique argument. DETR: detransitive. N: inclusive dual/plural. R: reflexive. I/INV: inverse number. IND:indicative mood. MOD: modal. DETR: detransitive.

We gloss morphological conditioning of stems with a subscript. Incorporated stems are glossed with $\mathrm{X}_{\mathrm{C}}$, for 'combining' stem, which is also found in nominal compounds like jòtchát [house ${ }_{\mathrm{C}}+\mathrm{door}$ ] 'house door'. Main verbs also have distinct perfective and imperfective stems, which will be glossed as $X_{P}$ and $\mathrm{X}_{\mathrm{I}}$, respectively. Uncited Kiowa examples are taken from fieldwork conducted in 2015, 2017, and 2018.
} 
A binding-verb analysis captures the interpretation well, and is related to classic approaches to weakest-scope indefinites (Carlson 1977; Heim 1982) and opaque intensional objects (Zimmermann 1993; Van Geenhoven and McNally 2005). It has also served as the basis for our understanding of pseudo-incorporation (Farkas and de Swart 2003; Dayal 2011) and weak definites (Schwarz 2014).

However, it comes with two costs. First, non-incorporating verbs do not quantify over their objects, so verbs either must shift from entity arguments to property arguments, or the language's verbs must have at least two versions in the lexicon. Lexical doubling might not pose a problem in languages where only certain verbs incorporate (Chung and Ladusaw 2006; Johns 2007). However, in languages where nearly any verb can incorporate nouns, it seems unlikely that they all double, especially given our modern understanding of decomposing verbal semantics. A systematic change like type-shifting might be more accurate, but it is unclear whether it occurs in the lexicon or the semantic composition.

Semantic Incorporation can be thought of as a version of type-shifting that comes with another, more crucial cost. It closes off the noun from further modification, but further modification is normal in West Greenlandic (3), where the free adjective phrase 'wooden' intersectionally modifies the incorporated 'airplane'.

\section{(3) West Greenlandic}

Suluut qisum-mik timmisartu+liur-puq.

S.ABS wood-INSTR.SG airplane+make-IND:INTR:3S

'Suulut made a wooden airplane.'

(Van Geenhoven 1998:100)

Van Geenhoven's solution to this problem involves recomposing the entire LF after it has already been built, to allow the adjective to be interpreted as the sister to the incorporated object. This works, but she admits this is an ad hoc solution, so it would require revisiting the architecture of the grammar without the offsetting gain of a better understanding of the process that results in incorporated noun interpretation.

In later work, Van Geenhoven (2002) proposes instead that these phrases are actually verbal modifiers rather than nominal ones: In (3), the modifier would indicate that the event's theme is wooden. Another approach (suggested by a reviewer) is that the modifier might be an appositive DP, along the lines of 'Suulut made an airplane, a wooden one.' In either case, this cost is attenuated, but the other remains.

An alternative approach to noun incorporation is Chung and Ladusaw's (2003, 2006) composition operation Restrict, which effects range restriction on the verbal function without changing its lexical meaning or closing off interpretation by binding.

(4) Chamorro (Chung and Ladusaw 2006:330)

Hayi gäi+patgun si Carmen?

who have+child DET Carmen

'Whose child is Carmen?' (lit. who child+has Carmen)

\footnotetext{
${ }^{2}$ Van Geenhoven's formalism has been updated to include Davidsonian events (of type $s$ ) and possible worlds (of type $w$ ). We also employ the routine omission of '=1' from each semantic conjunct.
} 


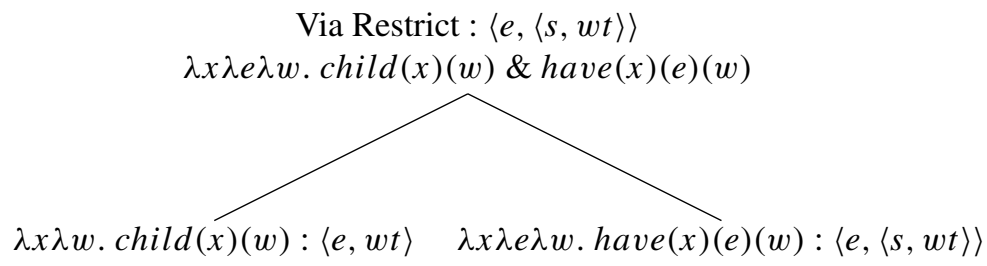

Crucially, Restrict leaves the noun's argument unsaturated, so it can be saturated by a DP later. As a compositional rule, it avoids the problems of Semantic Incorporation. However, when no other DP is used, Existential Closure is needed to bind the noun's argument and complete its interpretation, even when it is unmodified (6).

(6) Chamorro

Hayi gäi+patgun?

who have+child

'Who has a child?'

(Chung and Ladusaw 2006:329)

Existential Closure also captures the quantifier, but at the cost of a mismatch between the syntax and semantics. Assuming that the semantics is mapped directly from the syntax, any binder needs to be introduced by a syntactic head, so Existential Closure is not available on its own.

More to the point, both Existential Closure and Semantic Incorporation provide the necessary existential quantifier, but neither brings us closer to understanding how the quantifier is introduced. How do speakers interpret the noun's entity argument? If neither Semantic Incorporation nor Existential Closure are reliable mechanisms for binding that argument, this leaves us with a gap in the compositionality of object incorporation.

The central problem to the semantics of noun incorporation is the way the entity argument is interpreted. Both of the major well-understood mechanisms we have discussed involve conjunction of the noun with the verb, and an introduction of an existential quantifier. The latter is problematic due to concerns about the mapping of semantics from the syntax. The former is also a problem, because conjunction only applies when all of the noun's arguments, its entity and possible world, are identical to the corresponding arguments of the verb. This leaves conjunction out of the picture completely if the noun does not describe the theme of the verb, or is intensional. As (7) and (8) demonstrate, such cases do occur.

(7) Mohawk

wak-kon'tsher+rh-on

1S.PAT-paint+coat-STATIVE

'I have paint-coated it/painted it.'

(Mithun 2004:7)

(8) Kiowa

é-cítfî̀+tèndàu

$3 \mathrm{~s}: 1 \mathrm{sD}-$ meat $_{\mathrm{C}}+\mathrm{eat}_{\mathrm{C}}-$ want

'I want to eat meat.' (field notes) 


\section{Weak compositionality in non-object incorporation}

Weak compositionality is a more obvious issue when incorporated nouns are not objects of the verb. Much of the literature on noun incorporation focuses on object incorporation, especially the syntactic literature (see Massam's 2009 illuminating summary of this literature, and more recently Baker 2014; Barrie 2012; Barrie and Mathieu 2012, 2016; Heck and Richards 2010; Levin 2017, among others). Yet, for decades we have known of languages that contain incorporated nouns with other thematic roles, and no obvious morphology to indicate these roles. Two such languages are Mohawk, as in (9), and Chukchi (10).

(9) Mohawk (Mithun 2004, 2009)

a. ka-hseriee't+aneren-' NEUT-cord+tie up-STATIVE

'It is tied up with string.'

b. onke'nionhsókha' 'I leak from the nose.' ('My nose is running')

c. tentewaronta'serónnion' 'We'll build it out of logs.'

(10) Chukchi

tə-ralko=wajerken

1SG-tent $=$ sew

'I am sewing in the tent.'

(Spencer 1995:458)

Incorporated non-objects still require an existential binder over their entity argument, but they also require that a thematic role be assigned to it. We could thus propose a meaning for the verb in (9a) that includes an instrument role.

$$
\begin{aligned}
\llbracket k a h s e r i e ' t a ́ n e r e n ' \rrbracket=\lambda x \lambda e \lambda w . & {[\text { tie up }](x)(e)(w) \& } \\
& \exists y[\operatorname{string}(y)(w) \& \text { instrument }(y)(e)(w)]
\end{aligned}
$$

Such a meaning simply leads us to inquire how this meaning results from the overt parts. The specific thematic roles of the noun's entity may be left to the context, but its composition still requires some kind of mediating relation that links it to the event, because the noun's entity argument is not identical to that of the verb's theme. The question becomes more urgent in languages that generally only allow noun incorporation with these additional thematic roles, so the rest of this section focuses on two of these: Kiowa and English.

\subsection{Kiowa generally bars object incorporation}

Some languages go further than allowing non-object incorporation: They generally do not allow object incorporation at all. One such language is Kiowa. ${ }^{3}$ Incorporation is frequent in Kiowa (Watkins 1984), placing nouns and other stems

\footnotetext{
${ }^{3}$ English pronunciation: ['k $\mathrm{k}^{\mathrm{h}}$ ar.ov.wə], autonym: Cáuijōggà [kój.tồ:.gjà]. ISO code: kio. Kiowa-Tanoan group, spoken natively by a few dozen elders in Oklahoma, US. The Kiowa Tribe has not designated any official orthography. We employ one commonly-used orthography, devised by native speaker and self-taught linguist Parker McKenzie, with the addition of morpheme boundary markers. McKenzie and Meadows (2001) and Watkins and Harbour (2010) discuss this orthography's origins and linguistic intricacies. Roy (2007) and Neely and Palmer, Jr. (2009) discuss social and political aspects of orthography in the Kiowa community.
} 
between an agreement prefix and the main stem. Often, an adverbial co-occurs with an incorporated noun (13c). Besides placement, two other signals of incorporation are tone and conditioning. Incorporated stems often force the rest of the word's syllables to have low tone, and many incorporated stems have distinct forms when incorporated or used in compounds, like jố '[tó:] 'house', which when compounded or incorporated is jò '[tò:]. The phrases in (12-15) demonstrate the difference.

a. jố-cù á-bấ-hêl.

house-toward 3P-go - EVID

'they went home (I heard)'

b. á-jò̀+băn-ê.

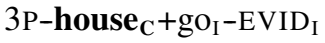

'they were headed home (I heard)'

(13) a. jó̀-cà á-chán-hèl.

house-at 3P-arrive ${ }_{\mathrm{P}}$-EVID

'they arrived home (I heard)'

b. á-jòtchán-hèl.

3P-house $_{\mathrm{C}}+$ arrive $_{\mathrm{P}}$-EVID

'they arrived home (I heard)'

c. á-âui+jò̀+chàn-hèl.

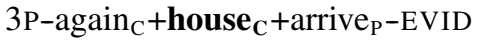

'they arrived back home (I heard)'

(14) èt-jò̀+chái

3I $>3$ D-house C $_{C}+$ ask.PFV

'They (3+) asked them (2) about a house.'

(15) Jò+chát-cà è-dé.

house $_{C}+$ door-at 3D-be standing

'They (2) stood at the door of the house.'

Despite widespread incorporation in the language, simple objects do not incorporate (16b)/(17b), barring exceptions that we will discuss in Section 5. This is even the case if the verb takes intransitive agreement (17c).

(16) a. Belle àn kåu $\varnothing-\quad$ âumàu.

B. HAB shawl 3s $>3 \mathrm{~s}-$ make.IPFV

'Belle makes shawls.' ('shawl' triggers singular agreement)

b. * Belle àn $\varnothing$ - káu+à̀umàu.

B. HAB $3 \mathrm{~S}>3 \mathrm{~S}-$ shawl $_{\mathrm{C}}+$ make.IPFV

'Belle makes shawls.'

(Adger et al. 2009)

(17) a. Háu chégùn à-bố?

YES/NO.Q dog 2S $>3$ S-see.PFV

'Did you see a dog?' 

b. * Háu à-chégùn+bò??
YES/NO.Q 2S > 3S-dog+see.PFV
Did you see a dog?'
c. * Háu èm-chégùn+bòn?
YES/NO.Q 2S-dog+see.PFV
Did you see a dog?'

Meanwhile, non-objects freely and routinely incorporate. In these cases, there is a corresponding use of a free nominal expression with a postpositive suffix. ${ }^{4}$ The incorporated noun can be interpreted with the same thematic role as it would have had under a postposition.

(18) Instrument

a. Màuchát*(-jò) à-sébé.

point-with.INSTR $2 \mathrm{~S}>3 \mathrm{~S}-\mathrm{stab}_{\mathrm{P}}$.IMPER

b. ̀̀-màuchát $(*$-jò $)+$ sèbè.

$2 \mathrm{~S}>3 \mathrm{~S}-$ point $_{\mathrm{C}}+\mathrm{stab}_{\mathrm{P}}$.IMPER

'Stick him with the pointy end.'

(19) Location

a. Thópòt*(-cà) dè-áu+sàugà.

shade-in 1S $>$ R-awhile ${ }_{C}+$ sit.PFV

'I sat down in the shade for a while.'

b. Dè-âu+thòpòt(*-cà)+sàugà.

$1 \mathrm{~S}>\mathrm{R}$-awhile $_{\mathrm{C}}+$ shade $_{\mathrm{C}}+$ sit.PFV

'I sat down in the shade for a while.'

(20) Natural Cause

Hègáu cáubót mîn dáu-góm+qáubèp!

then boat about to $3 \mathrm{I}: 1 \mathrm{PD}-$ wind $_{\mathrm{C}}+$ tip over.IPFV

'Our boat is about to capsize from the wind!'

(Jonah \& the Whale, Toyebo (n.d.))

A selection of other possible thematic roles can be found in (20)-(21); the corresponding free expressions are omitted for space.
a. Vehicle/Means
$\boldsymbol{k} \hat{a} \boldsymbol{u}+h \grave{o}+$ chàn $\mid\left[\mathbf{c a r}_{\mathrm{C}}+\operatorname{travel}_{\mathrm{C}}+\right.$ arrive $]$ 'arrive by car'
b. Material
tháp+kàui+àum-| [[deer ${ }_{\mathrm{C}}+$ skin $\left._{\mathrm{C}}\right]+$ make- $]$ 'make out of deerskin'

\footnotetext{
${ }^{4}$ At present, all Kiowa speakers are multilingual, and all speak English. However, we are certain that the similarities listed here are not due to interference, for they are routinely found in the data from the fieldwork done by J.P. Harrington in the 1920s, which often involved monolinguals. The similarities remain robust in modern speakers.
} 
c. Affected Body Part dè-ául+sôjàu | [1S > R-hair ${ }_{\mathrm{C}}+$ brush $_{\mathrm{P}}$ :MOD] 'I will brush my hair'

d. Similarity màyí $+\underline{a} g a ̀ a ~\left[w_{0} a_{C}+\right.$ be sitting] 'be sitting like a woman'

e. Kin relation $\underline{e}-f a ́ b i ́ t+q a ̀ u \mid\left[3 \mathrm{~s}: 1 \mathrm{sD}-\right.$ brother $_{\mathrm{C}}+$ lying down] 'he's my brother'

f. Other relation

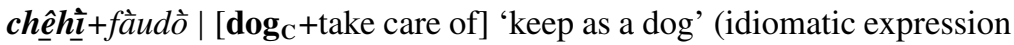
meaning 'treat harshly,' Harrington (1928:130))

g. Goal jò̀+bấ- | [house C $^{+g o-]}$ 'go home'

h. Source j’ó $+z o ̀ n-\mid\left[\right.$ shoe $_{\mathrm{C}}+$ pull out-] 'take out of (one's) shoe'

Many thematic roles can be expressed with incorporation, but many are restricted. Agents and recipients are not incorporated in Kiowa, or in any language (22).
a. Qậhî é-góp!
man $3 \mathrm{~S}>1 \mathrm{~S}-$ hit.PFV
'A man hit me!' (agent)
b. * É -qåâ̂+gòp!
$3 \mathrm{~S}>1 \mathrm{~S}-\operatorname{man}_{\mathrm{C}}+$ hit.PFV

Barrie and Li (2015) find that incorporation of non-objects also does not allow benefactive, recipient, or comitative roles. Their discussion of incorporation focuses on the Iroquoian language Onondaga, in which non-object incorporation (23b) also replaces postpositional usage (23a), but not with these roles.

(23) Onondaga ${ }^{5}$

a. o-hah-? $-*(\mathrm{keh}) \quad$ hati-dahke-?

NPREF-road-NFS-LOC 3PM.AGT-run-PURP

'They are running on a road.'

(Barrie and Li 2015:180)

b. hón-at-hah+dahke-?

3PM.PAT-SRFL-path+run-PURP

'They are walking/running on a path.'

$$
\begin{aligned}
& \text { * e-khe-atci+hsa-a-k ne? } \text { owihsa? }^{\text {? }} \text { FUT-1s>3FEM.INDEF-friend-nzlr-apply-PUNC NE butter } \\
& \text { 'I will butter it for my friend.' }
\end{aligned}
$$

Kiowa non-object incorporation exhibits the same restrictions. Comitatives are built with conjunction (26).

\footnotetext{
${ }^{5}$ Glossing used only in these Onondaga examples: NE: determiner-like nominal particle; NPREF: nominal prefix; NFS: noun-forming suffix; 3PM: 3rd plural masculine; PURP: purposive; SRFL: semi-reflexive.
} 
(25) a. Cóm gáu-ấumê.

friend $1 \mathrm{~S}>3 \mathrm{I}: 3 \mathrm{SD}$-make.PFV

'I made it for a friend. (benefactive)

b. * Gáu-cóm+à̀umè.

$1 \mathrm{~S}>3 \mathrm{I}: 3 \mathrm{SD}-$ friend $_{\mathrm{C}}+$ make.PFV

(26) a. Qậhî gàu á-chàu-dè è-chán.

man and 3-mother-3 3D-arrive.PFV

'A man came with his mother.' (comitative)

b. * Qậhî $\varnothing /$ è-cháu+chàn.

man $3 \mathrm{~S} / 3 \mathrm{D}-$ mother $_{\mathrm{C}}+$ arrive.PFV

\subsection{Intensional thematic roles}

We have seen that an incorporated noun can have a different entity argument than the verb. It can also have a different world argument when the replaced postpositive would take an intensional complement, as in the case of 'like'. In (27a), taken from a story, the incorporated noun báuláu 'butter' is the substance that the actual object gómjấgá 'mentholatum' [wind+grease] resembles in its way of being eaten. The butter does not have to be any particular butter in the actual world. Elicitation outside of the story's context finds that the sequence [butter+eat] cannot mean 'eat butter' (27b). Instead, the non-incorporated form must be used $(27 \mathrm{c})$.

a. Góm+jấgá á-dậumê gàu $\varnothing$-báuláu+fà̀ulè.

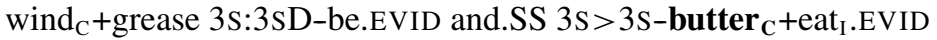

'He had mentholatum and was eating it like butter.' (Watkins 1990:417)

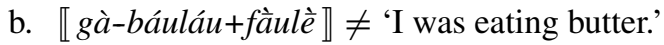

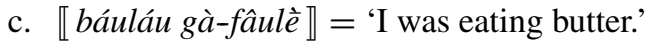

The incorporated form corresponds to a free expression, which also involves intensional butter.

(28) Báuláu-chò gà-fáutjàu.

butter $_{\mathrm{C}}$-like $1 \mathrm{~s}>3 \mathrm{~s}$-eat.IPFV

'I was eating it like butter.'

Intensional nouns differ from the verb in both arguments-its entity is not that of the verb's theme, and its possible world is not that which the verb describes. Instead, some intensional operator must bind the incorporated noun's world argument to attain an intensional reading - if he were eating butter in some world, he would be doing so in the way he actually ate the mentholatum. Essentially, this is the meaning of the adposition 'like', in Kiowa - chò [tsò]. In (29), we can characterize a similarity relation as being true when in the relevantly circumstantially similar worlds where butter is 
eaten, the butter-eating events are like the main verb's event of eating mentholatum, which is represented by the variable $x_{2} .{ }^{6}$

$\llbracket$ báuláu $+f a ̀ u-x_{2} \rrbracket=\lambda e \lambda w$. eat $\left(x_{2}\right)(e)(w) \&$ in all worlds $w^{\prime}$ relevantly like $w$ where an eating of $x_{2}$ occurs, that event occurs as if there was some butter in $w^{\prime}$ involved.

In cases like (29), both the world and entity argument of the incorporated noun are bound. As we saw with the Mohawk verb in (9a), describing the noun+verb's meaning does not help us explain the source of the meaning that is not brought by the noun and the verb.

\section{Proposal: Mediating relations in incorporation}

Let us take stock. The incorporation of object nouns exhibits weak compositionality because the source of the existential binder is not obvious. The incorporation of non-object nouns exhibits even weaker compositionality, because something needs to existentially bind the noun's entity argument and relate it thematically to the event. Further, some non-object incorporation must also bind the noun's world argument.

We contend that these compositional gaps are actually linked, and propose that in each case, a single mediating relation fulfills these needs, binding the noun and assigning it a vague thematic role when required. Incorporated themes are given a role by the verb and share arguments with it. Consequently, they do not require mediating relations to compose with the verb. However, they still need a relation above the verb to bind the entity argument. In the absence of a mediating relation, an incorporated noun never gets interpreted.

\subsection{The process of non-object incorporation}

We propose that mediating relations are introduced by functional heads that merge inside the verb's projection, rather than functional heads that project adjuncts to the clause. This means that we adopt an approach where incorporated nouns are merged in the syntax rather than the lexicon, and base-generated inside the verb rather than moved. Noun incorporation has been derived in a large number of ways (Sadock 1980; Mithun 1984; Baker 1988; Rosen 1989; Baker 1996; Compton and Pittman 2010; Harley 2011:inter alia), and it is likely that significant variation exists across languages (Baker 2009). This argument will thus focus on Kiowa, where a base generation account works, and emphasize the role that the interpretation plays in revealing structure.

Under this approach, the incorporation process begins in the numeration. When constructing a sentence with no incorporation, the speaker can add to the numeration a functional head that binds a noun's entity argument (such as a determiner) as well

\footnotetext{
${ }^{6}$ This similarity relation is essentially the semantics of like, which is fraught with difficulty due to its interaction with ellipsis and donkey anaphora, either of which suffices to take us well beyond the scope of this paper. The version here is crude but works enough for our purposes here. We do not intend it to be the final word on the matter.
} 
as one that assigns it a thematic role (viz., adpositions or verbal/inflectional heads). In (30a), those heads are at $\mathrm{D}^{\circ}$ and $\mathrm{P}^{\circ}$.

a. Tháp+kàui-jò hóldà gàt-ấumé. deer $_{\mathrm{C}}$ +hide-INSTR shirt $1 \mathrm{~S}>3 \mathrm{P}-$ make.PFV

'I made a shirt with/out of buckskin.'

b.

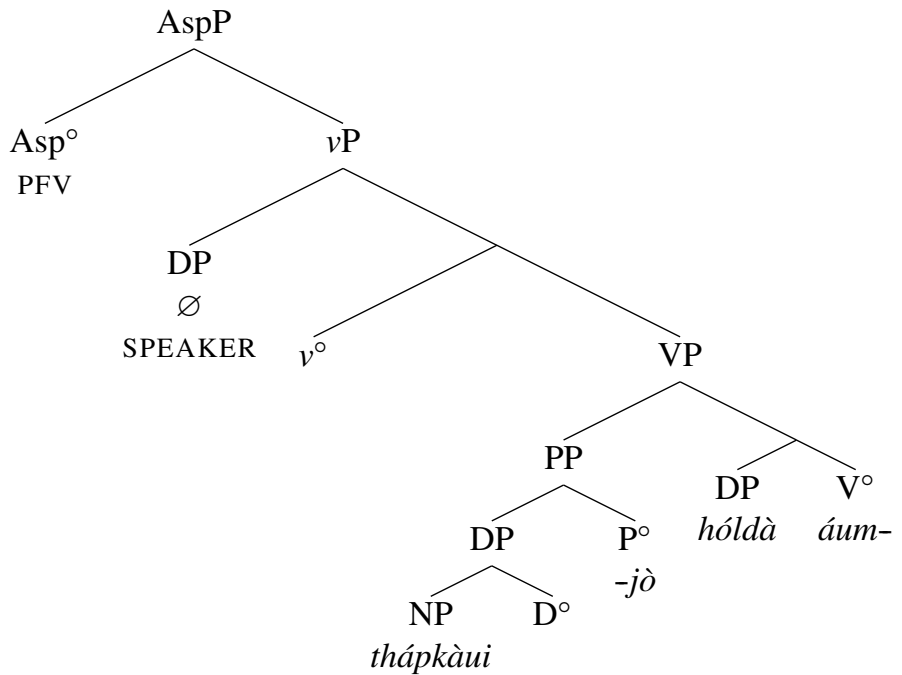

With incorporation, these functional heads are not numerated. One of the oldest and most consistent observations about incorporated nouns is that they lack the functional structure that full NP/DPs do. If the bare noun is not incorporated, it would be syntactically unlicensed and semantically uninterpretable. If there were only a determiner, the nominal would falsely lack any thematic relation to the verb in the semantics, and its meaning could not compose.

Incorporation is observed to obviate these problems, but the overt lexical heads do not suffice to allow the incorporated structure to be interpreted-this is the weak compositionality problem. Instead, we propose that a functional head in the verbal projection $\left(\mathrm{Z}^{\circ}\right)$ does the duty of the thematic adposition and the determiner. This head is inserted between the verb and the noun, which we assume to be directly merged into the verbal expression.

a. Hóldà gàt-tháp+kàui+ằmè̀.

shirt $1 \mathrm{~S}>3 \mathrm{P}-$ deer $_{\mathrm{C}}+$ hide+make.PFV

'I made a shirt with/out of buckskin.' (hóldà 'shirt' is lexically plural)

\footnotetext{
${ }^{7}$ It is not obvious that Kiowa nominal expressions form DPs, as there are no overt determiners. Harbour (2007) argues that inverse number morphology is hosted by $\mathrm{a} \mathrm{D}^{\circ}$ head, and incorporated nouns cannot bear this morphology. Ultimately, what is crucial is that full nominal expressions contain functional morphology (and the semantics thereof) that incorporated nouns lack.
} 
b.

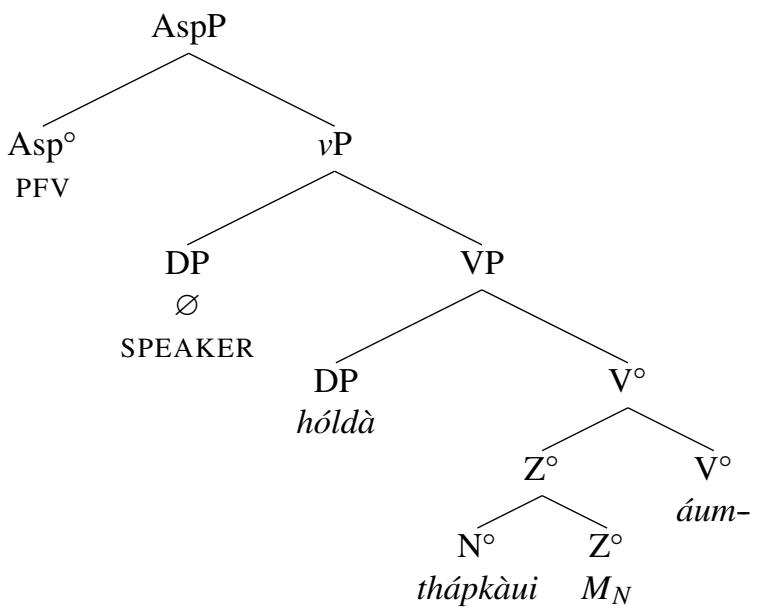

This head is not overt in productive Kiowa incorporation, although some fixed compounds and expressions do contain a string -fá/bá ([-pá/bá]) that may reflect its historical overtness (32). The head introduces a mediating relation $M_{N}$ that quantifies over the noun's entity and relates it thematically to the verb with the ROLE relation (33). This relation takes a property of entities and returns a property of events.

èm-ául+fá+cómgàu

$3 \mathrm{~S}>\mathrm{R}-$ head $_{\mathrm{C}}+\mathrm{FA}+$ shake.PFV

'he shook his head (to say no)'

$$
\llbracket M_{N} \rrbracket=\lambda P_{e w t} \lambda e_{s} \lambda w_{w} \cdot \exists y[P(y)(w) \& \operatorname{RoLE}(y)(e)(w)]:\langle\langle e, w t\rangle,\langle s, w t\rangle\rangle
$$

The RoLE relation results from a choice function over thematic roles. It allows the speaker to select the thematic role freely. This freedom reflects the facts in Kiowa (seen above), and long-standing observations of oblique or non-object incorporation (Spencer 1995; Mithun 2004:i.a.). However, this freedom is far from total; the selection is subject to certain systematic exceptions that we will address in Sect. 4.3.

In the semantic interpretation, the noun is interpreted as an argument of $M_{N}$.

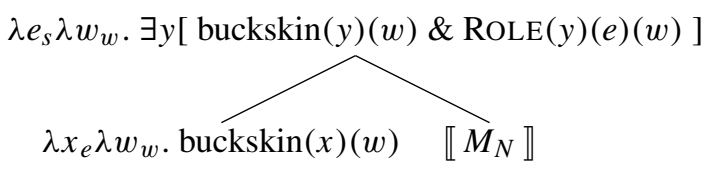

The result can conjoin with the verb through Event Identification (Kratzer 1996).

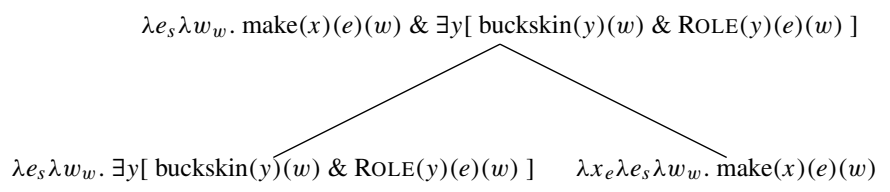




\subsection{Details on the existential quantifier}

The requirement that the noun be bound by the mediating relation ensures that the noun carries low scope.
a. Jé sâdàu
xó̀-jò
ê-qìgà.

all child:INV rock-INSTR 3I>1S-throw.PFV

'All the children threw a rock at me.'

(lit. all the children threw-at me with a rock)

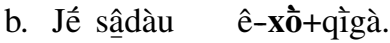

all child:INV 3I $>1$ S-rock C $_{\text {throw.PFV }}$

'All the children threw rocks/a rock at me.' $(\forall>\exists / \# \exists>\forall)$

Consultant comment: "They all had their own rocks."

A lot of incorporated nouns in Kiowa are translated with definite expressions. This definiteness can seem weaker (37) or stronger to the point of proper names (38) or even possessed items (39) (compare to Spencer's 1995 discussion of similar facts in Chukchi). ${ }^{8}$

\section{Bé-chát+hếdè!}

$2 \mathrm{~S}>3 \mathrm{I}$-entrance $\mathrm{C}_{\mathrm{C}}+$ remove $_{\mathrm{P}}$.IMPER

'Open the door/tipi flap!'

Á-Énédàukò+bà.

3P-Anadarko ${ }_{\mathrm{C}}+$ go.PFV

'They went to (the city of) Anadarko.'

(39) Béthàu ét-qól+tà-hèl.

apparently $3 \mathrm{I}>3 \mathrm{P}-$ neck $_{\mathrm{C}}+$ sever/PL $\mathrm{P}_{\mathrm{P}}$-EVID

'They ${ }_{1}$ had apparently cut their ${ }_{2}$ heads off.' (Osage Massacre)

(40) Bé-ául+mâbòp.

2S $>$ R-head C $_{\text {-nod.IPFV }}$

'You were nodding your head.' (not just any head)

Assuming that names denote properties that often take a null determiner in a full DP (Elbourne 2005), they can be incorporated as bare nouns. Their binder can still be an existential quantifier, with pragmatics providing enough domain restriction on the quantifier to make the meaning seem unique in the context. ${ }^{9}$ For instance, there is only one Anadarko, so if you go to an Anadarko, you go to the Anadarko.

Below, we walk through the process for ául+mâbòp 'nod one's head', from (40). The noun $\mathrm{N}^{\circ}$ combines with $\mathrm{Z}^{\circ}$, which introduces the mediating relation $M_{N}$. The speaker selects a role of 'affected part'; the noun describes the affected part of the theme.

\footnotetext{
${ }^{8}$ Note that these examples mostly involve apparent objects, but we will explain how they work in the next paragraph and Sect. 5 .

${ }^{9}$ We might also include further domain restriction in the existential quantifier, if we want to rely a bit less on the pragmatics: $\lambda e \lambda w . \exists x[[\mathrm{C}(\mathrm{x})(\mathrm{w}) \& \operatorname{Anadarko}(\mathrm{x})(\mathrm{w})] \& \operatorname{RoLE}(\mathrm{x})(\mathrm{e})(\mathrm{w})]$.
} 
(41) $\llbracket$ AFFECTED PART $\rrbracket=\lambda x \lambda e \lambda w . x$ is the affected part of the theme of $e$ in $w$

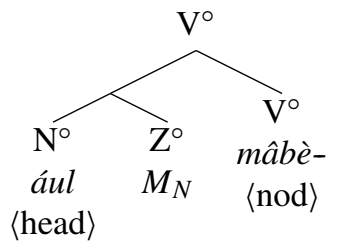

In the semantic interpretation, the noun is interpreted as an argument of $M_{N}$, and the result gives the set of events whose themes have a head affected by the event. Since each of these themes has but one head, the noun is interpreted as if it were definite. The result conjoins with the verb, which then can be saturated by the object- the person whose head is affected.

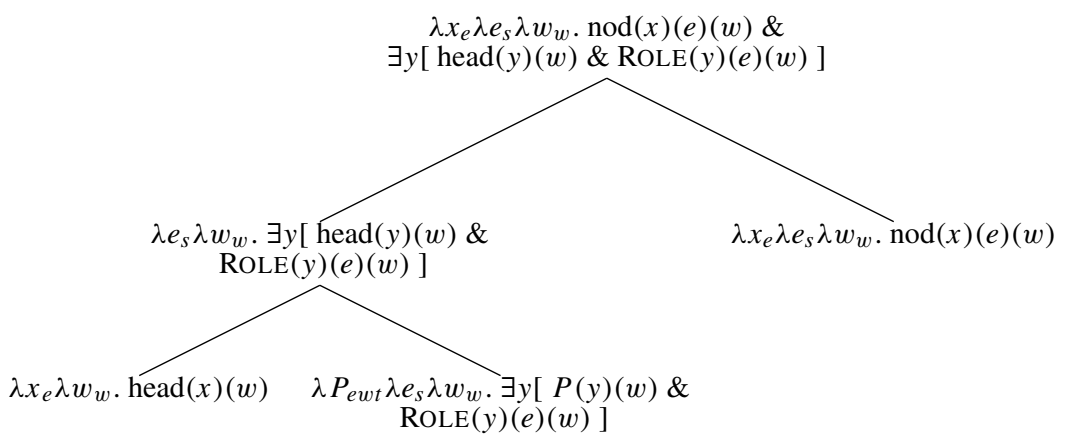

Naturally, we predict that if a person has more than one head, an indefinite sort of reading would ensue. Such contexts were odd for my speakers, but incorporating máun 'hand' triggers this effect easily.

(44) Gà-máun+thát.

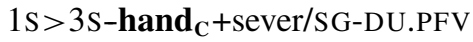

'I cut off his hand(s).'

\subsection{Restrictions on the selection of thematic roles}

The RoLE relation in the denotation of $M_{N}$ provides for the speaker to select the thematic role freely, but not all thematic roles are available. For instance, why can't Kiowa speakers use $M_{N}$ to incorporate agents or themes? Looking through Kiowa cases where certain roles are unavailable, we find three main kinds of exceptions to free selection of thematic role with $M_{N}$ : Roles that are pragmatically difficult, roles that are duplicated, and roles that are ruled out independently. These exceptions are all caused by factors external to the thematic assignment, so we can maintain ROLE as a choice function over the set of thematic roles, whose output is subject to external constraints on interpretation.

Pragmatically difficult roles are rejected by speakers. For instance, (30a) is rejected on meanings like 'made a shirt inside a buckskin.' Since these are pragmatically difficult, the rejected meanings can be coerced, but only with difficulty, and 
speakers will impatiently add hesitant comments like "I guess you could say that." This pragmatic effect is not limited to incorporation. In nominal compounds, similar pragmatic restrictions apply: són+qàuàl- [grass+bucket-] means 'basket' rather than 'bucket for grass', but you can coerce such a reading. Within these compounds, functional heads assign contextually selected relations between the nouns (Jackson and Punske 2013). The effect makes sense if we assume that compounds and incorporation structures are made in the syntax, but we allow that certain complex structures can be lexicalized to push us towards a particular thematic role/nominal relation. The lexicalized meaning usually crowds out other interpretations due to the effort they require. To give an English example, a duck pond is a pond for (intensional) ducks, but with effort one could conceive a scenario where it means 'a pond shaped like a duck'.

Following the Theta Criterion, we predict that speakers also cannot incorporate non-objects with one thematic role and use the same thematic role elsewhere in the same sentence. This is the case. For instance, if a noun is incorporated as an instrument, an instrument cannot be added.

$$
\begin{aligned}
& \text { * Â+tō-jò } \quad \text { gà-máun+góp. } \\
& \text { wood }_{\mathrm{C}}+\text { club-with } \\
& \text { (to mean *'I hit him with my hand with a stick.') }
\end{aligned}
$$

The third restriction is more complex, but it shows that the syntactic derivation plays a role in restricting incorporation. We saw that certain thematic roles are never incorporated, in Kiowa or in other languages: Agents, Benefactives, Comitatives, and Recipients. We proposed that non-object incorporation involves alternative numeration that feeds the semantic interpretation: Instead of adding a thematic role through a functional head that takes a DP argument, one adds it with a functional head that takes an $\mathrm{N}^{\circ}$ argument. This process leads us to infer that these roles cannot be incorporated, either because they cannot be alternatively numerated, or because they would be uninterpretable.

The inability to incorporate agents is straightforward: The head that introduces them is simply too crucial. Agent roles are introduced by agentive $v^{\circ}$. The verb selects for this head, so it cannot be omitted. Besides, its omission would leave the object caseless and unlicensed. Thematic roles cannot be doubled, so if the Agent role is assigned by a mediating relation, it cannot be assigned by $v^{\circ}$.

Comitatives are made in Kiowa with conjunction, so they will share the role with their conjunct and not feature in incorporation structures.

Benefactives and recipients in Kiowa are trickier. They are introduced by the applicative head $\mathrm{Appl}^{\circ}$ (Harbour 2007), which affects argument structure. At first it is not clear why APPL cannot be alternatively numerated, because only a handful of ditransitive verbs require it (like $\underline{a} u$ ' 'give'). It also does not assign a specific thematic role that cannot be used elsewhere, because it is used for benefactives, recipients, possessors (20), affected persons, and even the agents of out-of-control/manage-to readings.
Hágá yá-hếdái-thàu
nègáu
bà-bá.

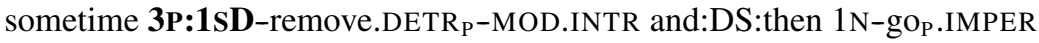

'If I can get things cleared away, let's go.'

(Watkins 1984:144) 
Barrie and $\mathrm{Li}$ (2015) propose that the heads that introduce these assign to them a 'differentiated' case, which is linked to a particular thematic role. Incorporable thematic relations are assigned by heads with 'undifferentiated' case that merely license DPs without linking to a particular role. However, this characterization does not apply to the Kiowa $\mathrm{Appl}^{\circ}$ head, which links to many distinct roles.

The Applicative does affect argument structure, and that is reflected in the verb agreement. Since these roles are are introduced by $\mathrm{Appl}^{\circ}$, we can distinguish in Kiowa between functional heads that are along the extended verbal projection and contribute to agreement, and those that are not. Those introduced along the extended verbal projection are tightly linked to argument structure, so we can conclude the existence of a condition on numeration that prevents the alternative numeration of argument-selecting heads for incorporation.

Barrie and Li suggest that these heads interact with argument structure because the case they provide is linked to specific thematic roles. If we step back a bit, we see an implied suggestion: The way that a head provides thematic information matters. $\mathrm{A} \mathrm{P}^{\circ}$ head is functional, licensing a DP with functional features, but also brings with it lexical content that supplies the thematic relation. The $\mathrm{Z}^{\circ}$ head replaces this lexical content in the numeration. In contrast, the functional heads of the extended verbal projection supply thematic content through their functional features. That is to say they lack additional lexical material that could supply this thematic content- they are canonically weakly expressed, and agentive $v^{\circ}$ rarely if ever is expressed morphologically. Thus the only supplier of these heads' thematic content is the feature we assume it to bear. If we assume that a syntactic feature crucial to the argument structure cannot be incorporated, we have a difference that prevents alternative numeration, and that in turn blocks incorporation of those heads' arguments.

Having ruled out those thematic roles, what about themes? This question brings us to object incorporation. Kiowa generally lacks it, and the external constraints discussed here all rule out incorporating themes. Theme roles are assigned by the verb, which obviously cannot be alternatively numerated and set aside. If ROLE is used to choose a Theme role, that role will be duplicated by the verb. This restriction is problematic, though, in light of languages like West Greenlandic, Chamorro, or Mohawk, which do allow object incorporation. It is even more problematic in light of a language like Southern Tiwa (ISO: tix) which usually requires objects to be incorporated (Allen et al. 1984). If theme roles are syntactically barred from incorporation, how can objects ever be incorporated through the $\mathrm{Z}^{\circ}$ head?

Logically, we have to conclude that some other mechanism is at work for object incorporation. What might that look like? It has to involve existential quantification over the noun's entity argument, because without it the incorporated noun's entity argument never gets saturated. However, it cannot involve thematic role assignment, because the theme receives its assignment from the verb itself rather than a functional head, and this role cannot be taken away from the verb in Kiowa or duplicated by another head.

We can gain a sense of what this mechanism is by exploring contexts where object incorporation is allowed Kiowa. It is generally not allowed, but in certain systematic environments, it is not only licensed, but is fully productive. The next section investigates them, and demonstrates that there are two mechanisms that allow theme incorporation. 


\section{Contexts that license object incorporation}

Kiowa generally disallows object incorporation (16b), but in some contexts it is licensed. Namely, it is licensed in the categorization process that contributes to derivation, and as the object of verbs that are themselves incorporated.

\subsection{Exceptional case 1: Derived lexical items}

In Kiowa, verbs describing culturally or otherwise salient activities that Mithun (1984) calls 'nameworthy' can have incorporated objects, including having babies or opening doors. The object/theme still triggers agreement. ${ }^{10}$

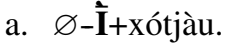
$3 \mathrm{~S}>3 \mathrm{~s}-$ offspring $\mathrm{C}+$ put down/SG.IPFV
'She's having a baby.'
b. Gàt-’ét+zâuimàu.
$1 \mathrm{~S}>3 \mathrm{P}-$ bread $_{\mathrm{C}}+$ mash. IPFV
'I'm kneading the dough.'
c. Bé-chát+hếdè!
$2 \mathrm{~S}>3$ I-entrance ${ }_{\mathrm{C}}+$ remove $_{\mathrm{P}}$.IMPER
'Open the door/tipi flap!'

(Harrington 1928:85)

One might ask if these structures actually involve a null/pro object with the noun added to indicate similarity or relation ('put it down as a baby,' 'open it like a door'). However, the object agreement facts of these nouns makes it clear what the object is, especially chát 'door', which triggers inverse agreement in the singular, and $\hat{e}$ 'bread/dough', which is a mass noun that triggers plural agreement.

This exception has no clear explanation from a purely syntactic perspective. If these verbs are impossible to build at all, they certainly are here. Under the semantic approach presented here, the syntax can actually build noun-verb word structures, but the semantics cannot interpret them without help from a mediating relation. We cannot place a mediating relation below the verb without cutting off the noun from the theme role. Therefore a head has to introduce the mediating relation above the $\mathrm{N}^{\circ}+\mathrm{V}^{\circ}$ structure. The relation cannot be $M_{N}$, due to type reasons. Instead, it takes a verb relating entities to events, and returns a property of events. Let us name this relation $M_{V}$. In its denotation (48), we have added a domain restriction condition $C(y)(w)$ to maintain a tripartite quantifier structure.

$$
\llbracket M_{V} \rrbracket=\lambda P_{e, s w t} \lambda e_{s} \lambda w_{w} . \exists y[C(y)(w) \& P(y)(e)(w)]:\langle\langle e, s w t\rangle,\langle s, w t\rangle\rangle
$$

\footnotetext{
${ }^{10} \mathrm{~A}$ reviewer asks if opening a door is really culturally salient. We do not expect that 'nameworthy' salience has to be cultural in nature, and in any case cultural reasons can vary significantly. Cases like this one may simply involve an expression common enough for speakers to lexicalize it to some extent.
} 


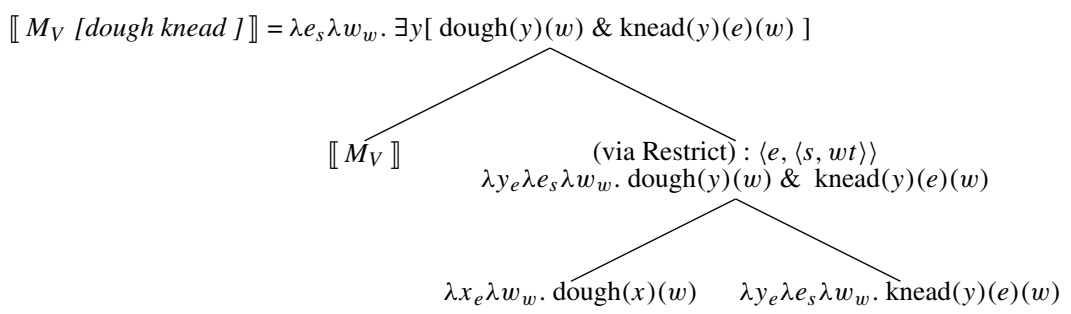

How is this structure built in the syntax? This structure only occurs when the verb is lexicalized. We assume that all structure that is built gets built in the syntactic computation. Thus, with the term 'lexicalized,' we simply mean that speakers can store certain strings and structures. The triggers for this lexicalization are those that lead to 'nameworthiness' and other coinages. In the process of lexicalization, speakers place an expression into a syntactic category by using a categorizing head. Since the structures in question are verbs, we will employ $\mathrm{V}^{\circ}$ as a categorizing head that provides a new syntactic head for the expression. This head can not only categorize the structure, but carry the mediating relation $M_{V} \cdot{ }^{11}$

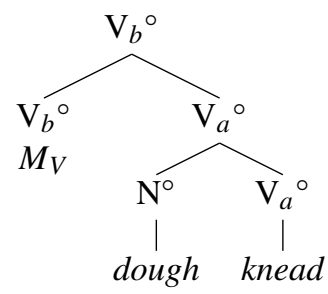

Note that we still assume this process to take place in the syntax. This structure can then be lexicalized. However, that does not entail that speakers generally draw these structures out of the lexicon into the numeration. For most cases, it works equally well if speakers build these structures each time they are used, and the lexically stored version crowds out other possible parses or interpretations by the listener. We can see how crowding out works with a synthetic compound like can opener. We build it each time we say it, but we also have a lexical item that the string maps to, describing a family of cutting tools designed specifically to open cans. Now, we could use all sorts of tools to open cans, like a pocketknife. We can call those things can opener in an ad hoc fashion. Yet in ordinary use, without a special context like we have described, an utterance of can opener will trigger the lexical entry, and the hearer will think of the specific tool. If someone sent you to buy a can opener and you came back with a pocketknife, you would have failed.

The link to categorization offers an explanation of why object incorporation is not very productive in Kiowa. Essentially, the acceptability of novel compound forms varies across languages. Kiowa speakers are not fond of novel word creation generally, so it stands to reason that they are not accepting of other categorization processes, like productive object incorporation. We predict that languages that allow productive object incorporation will also allow more productive compound-making generally.

${ }^{11}$ We subscript category heads simply to aid the reader. 
Once a built structure has been lexicalized, speakers may eventually cease to treat it as a composed unit. At that point, speakers can draw it from the lexicon as one piece, and as a simple lexical item, its meaning can drift. For instance, the Kiowa phrase máun +càum [hand ${ }_{\mathrm{C}}+$ show] means 'point'. However, it is rude in Kiowa culture to point with the hand or fingers. Instead, one points with the lips, which is described as bél+máun+càum [lip ${ }_{\mathrm{C}}+$ hand $_{\mathrm{C}}+$ show]. The bleaching of máun indicates that a more accurate gloss is actually bél+máuncàum [lip ${ }_{\mathrm{C}}+$ point], where the stem [hand $\mathrm{C}_{\mathrm{C}}+$ show] has become nameworthy enough to be lexicalized and then eventually to lose its compositionality. Even idiomatic NI-verbs can emerge, like thól+óbàkài [saliva+swallow] 'crave after' or thó+háu [face+take] 'kiss', using the same process.

\subsection{Exceptional case 2: Verbs embedded within nominals}

Essentially, object incorporation is licensed if and only if there is a mediating relation above the verb+noun collocation. This relation does not offer a thematic role. Its presence is linked to categorizing heads, so we should see it elsewhere, and we do: Kiowa allows productive object incorporation in verbs within a nominal expression.

One type involves noun instruments created from a compound verb. This derivation process was commonly used to name new tools and technologies encountered after the confinement and acculturation programs began in the late 19th century. The following nouns exemplify the process.

(51) Derived nouns

a. dàum + sấ $\mid$ [ground $_{\mathrm{C}}+$ shatter $\left._{\mathrm{C}}\right]$ 'plow'

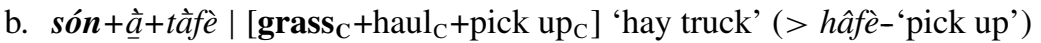

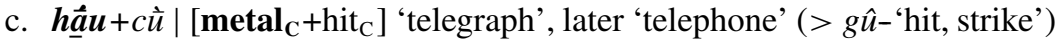

d. chát + tếdà $\mid\left[\right.$ door $_{\mathrm{C}}+$ remove $\left._{\mathrm{C}}\right]$ 'key' (> hếdà-'remove')

The final overt verb in these compounds is in its combining form, signaling that it is not the head of the construction. This suggests a null nominalizing head that gives a generic instrument reading. We end up with the set of individuals such that, if used as intended, there is an event where the individual opens a door.

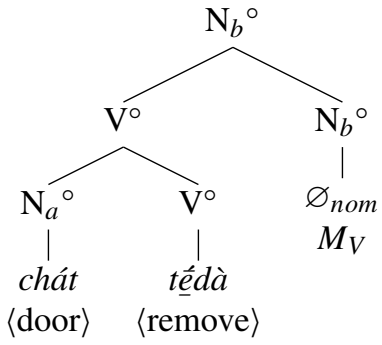

$M_{V}$ is a complicated relation, since it not only has to bind the incorporated noun, it has to bind an event and do the work of an external argument head, assign the agent its thematic role and link it all to the nominal entity of which the entire expression is a property. In the case of (51d), the expression denotes a property of items such that when used for their purpose, they are instruments for opening doors. The preliminary denotation below demonstrates this complexity. 
$\llbracket(52) \rrbracket=\lambda x_{e} \lambda w_{w} . \forall w^{\prime}\left[\operatorname{circ}(w)\left(w^{\prime}\right) \& x\right.$ is used for its purpose in $w^{\prime} \rightarrow$ $\left.\exists e^{\prime}\left[\operatorname{instrument}(x)\left(e^{\prime}\right)\left(w^{\prime}\right) \& \exists y\left[\operatorname{door}(y)\left(w^{\prime}\right) \& \operatorname{open}(y)\left(e^{\prime}\right)\left(w^{\prime}\right)\right]\right]\right]$

We can decompose this relation, because the thematic assignment and the binding of entities are applied to distinct semantic arguments. We can adjust the LF to make the mediating function $M_{V}$ interpreted below the categorizing head at LF. It mediates between the compound verb and the categorizing head. This placement simplifies the meaning of $\varnothing_{\text {nom }}$ to one that takes a property of events and returns a property of entities that are proper instruments to any such events. This meaning permits the application of the $\mathrm{N}^{\circ}+\mathrm{V}^{\circ}$ complex to the mediating relation.

a. $\llbracket \varnothing_{n o m} \rrbracket=\lambda P_{e, s w t} \lambda x_{e} \lambda w_{w} . \forall w^{\prime}\left[\operatorname{Circ}(w)\left(w^{\prime}\right) \& x\right.$ is used for its purpose in $\left.w^{\prime} \rightarrow \exists e^{\prime}\left[\operatorname{instrument}(x)\left(e^{\prime}\right)\left(w^{\prime}\right) \& P\left(e^{\prime}\right)\left(w^{\prime}\right)\right]\right]$

b.

$\lambda y_{e} \lambda w_{w} . \forall w^{\prime}\left[\operatorname{Circ}(w)\left(w^{\prime}\right) \& y\right.$ is used for its purpose in $w^{\prime} \rightarrow$ $\exists e^{\prime}\left[\right.$ instrument $\left.\left.(y)\left(e^{\prime}\right)\left(w^{\prime}\right) \& \exists x\left[\operatorname{door}(x)\left(w^{\prime}\right) \& \operatorname{open}(x)\left(e^{\prime}\right)\left(w^{\prime}\right)\right]\right]\right]$

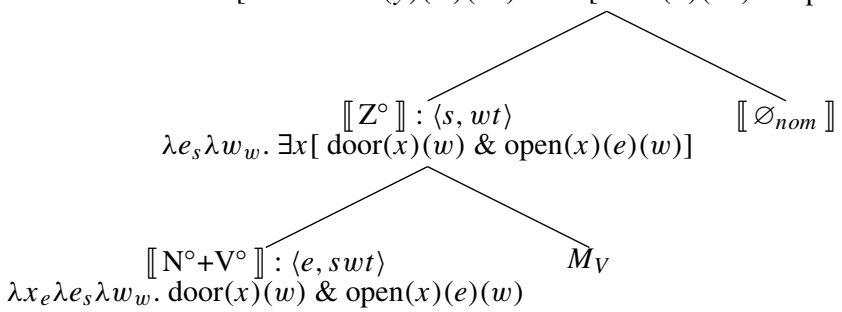

Bare nominalizations allow for object incorporation, so we predict that overt nominalizing processes also allow it, and they do. One involves compounds with nouns. The relation between the verbs and the nouns is interesting in its own right, but our focus is on the mediating relation that licenses the object incorporation.

$$
\grave{e}+q u ́+j \grave{o} \mid\left[\text { [grain } \mathrm{C}+\text { put/ } / \mathrm{PL}_{\mathrm{C}}\right]+\text { house] 'granary, silo' }
$$

$$
\text { són+tà+qàudàl | }\left[\operatorname{grass}_{\mathrm{C}}+\mathrm{sever} / \mathrm{PL}_{\mathrm{C}}\right]+\text { vehicle] 'lawn mower' }
$$

Another overt nominalization involves agentives (like English -er), which involves compounding with nouns or bound forms expressing various types of people.

$$
\text { agent/subject nominalizing }
$$
a. màutém+mà $\mid$ teach $_{\mathrm{C}}+$ woman 'teacher'

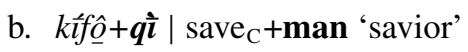
c. dế+gàu $\mid$ sleep $_{\mathrm{C}}+$ NOM.INVERSE 'sleeping ones'
d. $\hat{o}+\hat{e} l+j \underline{\grave{o}}+q \grave{\imath} \mid$ throat $_{\mathrm{C}}+$ be $\mathrm{big}_{\mathrm{C}}+$ speak $_{\mathrm{C}}+$ man 'camp crier' (big throated speaker)

(58) object nominalizing under second verb

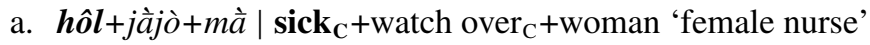
b. $s \underline{\hat{e}}+f \underline{\hat{t}}+g \grave{a ̀ u} \mid$ peyote $_{\mathrm{C}}+\mathrm{eat}_{\mathrm{C}}+$ NOM.INVERSE 'peyote eaters'
c. tháp $+\underline{e}+q \grave{l} \mid$ deer $_{\mathrm{C}}+$ hunt $_{\mathrm{C}}+$ man 'deer hunter' 
d. dàum + âuiàum $+q \grave{l} \mid$ earth $_{\mathrm{C}}+$ repair $_{\mathrm{C}}+$ man 'Earthmaker' (a holy figure, Kracht (2017:178))

These nominalizations can take any verb of type $\langle s, w t\rangle$ as their object, so either intransitives or simple verbs can be added (57), or transitives that have been made intransitive through application to a mediating relation that saturates their entity argument (58).

\subsection{Exceptional case 3: Control-like incorporation in Kiowa}

We have seen that Kiowa permits object incorporation in systematic contexts that involve a mediating relation being added immediately above the $\mathrm{N}^{\circ}+\mathrm{V}^{\circ}$ expression. The cases that we have seen involve category-forming heads that nominalize verbal structures. A third context is not tied to noun-building at all, but involves verb incorporation. The verb incorporation itself relies on a mediating relation, and this mediating relation can include the $M_{V}$ that binds the incorporated noun's argument.

Kiowa allows productive verb+verb structures for a number of purposes. For instance, two verbs can be combined to make a serial description.

(59) Serial description

a. Dè-kái+gùn.

1S $>$ R-stretch C $_{\text {jump.PFV }}$

'I jumped (up).' ( $\simeq$ I jumped myself up stretching)

b. $\llbracket k a ́ i+g u ̀ n-\rrbracket=\lambda x \lambda e \lambda w \cdot \operatorname{stretch}(x)(e)(w) \& \operatorname{jump}(x)(e)(w)$

Serial descriptions are the result of conjunction, when the two verbs share entity, event, and world arguments. In many other cases of verb incorporation, these arguments are not shared. For instance, an incorporated verb can be interpreted as if it were in a control structure or a tough-construction. In each case, the embedded verb's event and world arguments are distinct from those of the main verb.

(60) É-fóoténdàu.

$3 \mathrm{~s}: 1 \mathrm{sD}-$ see $_{\mathrm{C}}+$ want

'I want to see you.'

(61) Á-dàu è-têm+còt.

stick-INV 3I-break $\mathbf{C}_{\mathbf{C}}+$ be strong

'The stick is hard to break.'

(62) Á-cún+bà.

3P-dance ${ }_{\mathrm{C}}+$ go.PFV

'They went to dance.'

We call this phenomenon Control-like Incorporation (CI), because it shares with control two key semantic properties: It referentially links the embedded verb's subject or agent to an argument of the superordinate verb, and it determines a relationship 
between the two verb's events. It differs from control in that the structure lacks a PRO subject bound by a complementizer.

CI contexts correspond specifically to some types of control that Landau (2015) calls 'logophoric,' because they involve an attitude that binds the embedded world arguments. A proposition like 'they went to dance' expresses purpose: It holds if they went with an attitude such that in all worlds where that attitude holds, there is an event where they dance. It does not entail that they dance in the actual world.

(63) Áuphàu á-fớ+bắ, né háun gáu-bọ́mâu.

there 3 P-see C $_{\mathrm{C}}+$ go.PFV but not $3 \mathrm{P}>2 \mathrm{~S}$-see:NEG

'They went there to see you, but they didn't see you.'

The CI-verb's event and world arguments are bound by operators, so we cannot rely on conjunction. We might argue that controlling verbs provide these operators. However, in (62) there is no controlling verb or other overt morpheme to host them. Instead, we need a mediating relation. At first, we propose the LF in (65), where a functional head $\mathrm{X}^{\circ}$ licenses the embedded verb and inserts a mediating relation $M_{C}$ expressing an attitude relation that links the subject of the embedded verb to the subject of the main verb, whose mental state (or attitude) is associated to the event (66).

(64) À-chêềò̀+bànmà.

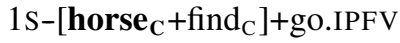

'I'm going to find a horse.'

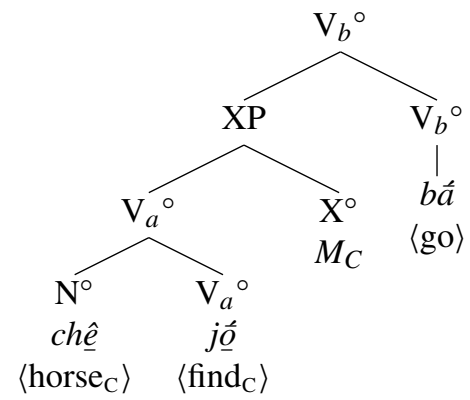

(66) Purpose relation and associated attitudes

a. Associated attitude

For any event $e$, let $a_{e}$ be an attitude associated with $e$, held by the agent or acting participant of $e$.

b. Content relation

For any worlds $w, w^{\prime}$, Cont $_{w}\left(a_{e}\right)\left(w^{\prime}\right)=1$ iff $w^{\prime}$ is compatible with the content of $a_{e}$ in $w$.

c. Mediating relation

$\llbracket M_{C} \rrbracket=\lambda P_{s, w t} \lambda e_{s} \lambda w_{w} . \forall w^{\prime}\left[\operatorname{Cont}_{w}\left(a_{e}\right)\left(w^{\prime}\right) \rightarrow \exists e^{\prime}\left[\right.\right.$ the agent of $e^{\prime}=$ the holder of $\left.\left.a_{e} \& \mathrm{P}\left(e^{\prime}\right)\left(w^{\prime}\right)\right]\right]$ 
The content relation does not specify that a purpose is involved because it does not specify the attitude. This comes from the selection by the speaker, subject to ordinary constraints on associated attitudes.

The mediating relation $\llbracket M_{C} \rrbracket$ takes an intransitive verbal expression (property of events) as its argument, and returns another property of events that can combine with a verb through some kind of conjunction. Essentially, just as $M_{N}$ replaces functional structure in the DP layer, $M_{C}$ replaces the functional structure in the CP-layer that Landau (2015) shows is involved with this kind of control in full sentences, by introducing the modal element and the link between the embedded argument and a matrix argument. Given how much variability there is in the modal and the link between arguments (object control, etc.), we expect there to be more to say about how control-like incorporation works. For now, it suffices to demonstrate that such a binder exists, because that is what will semantically license the object incorporation.

Employing $M_{C}$ captures the role of the agent of the embedded verb, but does not capture the existential quantification over its object. For that, the $M_{V}$ relation can be used, licensed by the categorizing $\mathrm{V}_{b}{ }^{\circ}$ head above it. It is merged at LF just above the $\mathrm{N}^{\circ}+\mathrm{V}^{\circ}$ complex.
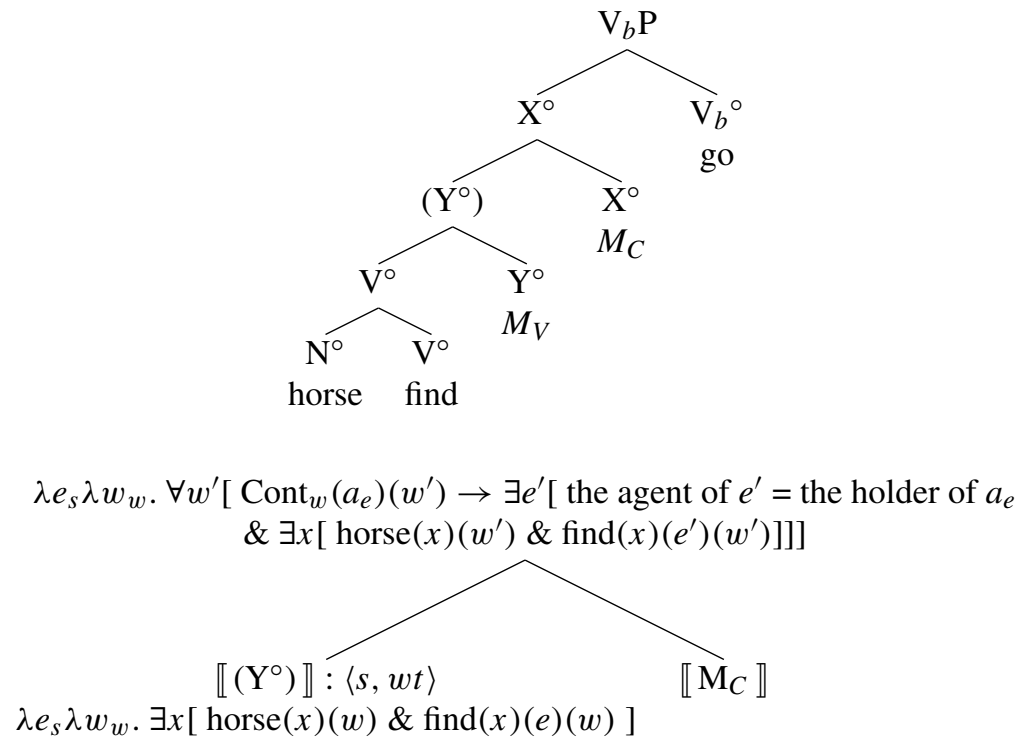

\subsection{Summarizing incorporation in Kiowa}

In this section we have seen three contexts where objects are incorporated routinely and even productively in Kiowa. Two are in clearly derivational contexts of nominalization, and one is under control-like verb incorporation. In each case, we find the need for a mediating relation, and link the availability of those relations to the categorizing process involved. The nominalizations involve noun-making heads, while the control-like cases involve a second mediating relation whose head $\mathrm{X}^{\circ}$ categorizes the phrase below it. 
Overall, by employing mediating relations we have made progress towards understanding the compositionality of noun incorporation. In doing so, we have distinguished two methods of building noun incorporation structures, each corresponding to a distinct semantic type of incorporation and a distinct syntactic process. For non-objects, speakers alternatively numerate the head that provides the thematic information, and insert a mediating relation between the noun and the verb. They can choose any thematic role they like, subject to external constraints of pragmatics, semantics, and syntax. For object incorporation, there is no alternative numeration of thematic information. Instead, the noun conjoins with the verb, and a categorizing head licenses a mediating relation above the noun+verb complex.

Since these two methods are distinct, we should expect both to be used together, and this can be the case (69). Speakers did not prefer these double-incorporations to forms with one free noun. We suspect the involvement of lexicalization in Kiowa object incorporation plays a role through crowding out.

Àn dé-àun+chát+hếdòp.

HAB $1 \mathrm{~S}>3 \mathrm{I}$ - foot $_{\mathrm{C}}+$ door $_{\mathrm{C}}+$ remove.IPFV

'I open doors with my foot.'

?? Gàt-àun+êt+zâuimàu.

$1 \mathrm{~S}>3 \mathrm{P}-$ foot $_{\mathrm{C}}+$ dough $_{\mathrm{C}}+$ mash.IPFV

'I'm kneading the bread with my foot.'

We also expect there to be multiple non-objects incorporated. These more frequently occur, and are readily accepted and produced by speakers. On occasion in stories, notably with affected body parts (72), and in names, which are generally compounds or nominalizations (71). In the case of body parts, the body part precedes the instrument. In the case of similarity, the first linear noun has an instrument role and the second expresses similarity. Still, it is rare to have two nouns incorporated in a Kiowa verb, even if it is normal to have several verbs and adverbials (73).

(71) $\varnothing$-Zép+tò̀+gòp.

$3 \mathrm{~S}>3 \mathrm{~S}-$ bow $_{\mathrm{C}}+$ club $_{\mathrm{C}}+$ hit.PFV

'He hit him using a bow like a club.' (name referring to a notable war incident)

Gàu 't-gúpól+qâu+sà̀ gàu

and:SS $1 \mathrm{~S}>3 \mathrm{~S}-$ rib cage $\mathrm{C}_{\mathrm{C}}+\mathrm{knife}_{\mathrm{C}}+$ tear.PFV and:SS

't-sául+qàu+dàuigàu.

$1 \mathrm{~S}>3 \mathrm{~S}$-guts+knife ${ }_{\mathrm{C}}+$ tear out.PFV

'And I opened her up under the ribs and disemboweled her.' (Wagon Attack, Redbird (n.d.))

(73) À-âui+còdò+àultò+kòp+àumdè-hèl.

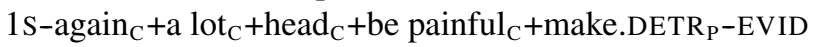

'I got a nasty headache again.' (the detransitive of 〈make〉 means 'become' here) 
This section largely encompasses the methods of how noun incorporation works in Kiowa, by showing how the possible structures are built, and how the impossible ones are prevented. In the next section, we will show how the same methods work in another language, English, and then we will see one other method of building object incorporation.

\section{Applying mediating relations to English}

English is another language that routinely allows noun-verb compounds, though their status as the result of a productive building process has long been disputed. Lieber (1992) for instance claims they are all back-formed from nominal compounds. However, Bauer and Renouf's (2001) corpus search turns up dozens of clear noun-verb, adjective-verb, and verb-verb compounds, and in any case, a back-formation account does not fill in the interpretive gap in the semantics of the noun-verb compound.

In agreement with Harley (2011), we treat noun-verb compounding as noun incorporation, although our motivation is ultimately semantic. In the semantics, English and Kiowa noun incorporation share the curious but robust restriction that object incorporation is generally not allowed, while incorporation of other roles is allowed and quite productive.

*We paper-wrote all weekend. $(=$ we wrote a paper all weekend)

a. Instrument: We hand-washed the dishes.

b. Means: They will pan-fry anything.

c. Location: Pratchett window-shops on Tuesdays.

d. Similarity: The bartender pimp-slapped the rowdy customer.

e. Performative We will test-release the new OS next week. role:

Also as in Kiowa, the incorporated noun may be intensional if the role calls for it. For instance the slang expression pimp-slap involves similarity, meaning to 'slap in the cruelly ostentatious manner of a pimp', whether that pimp is real or not.

These uses are essentially non-object incorporation, and can be built using the alternate numeration of thematic information.

a.

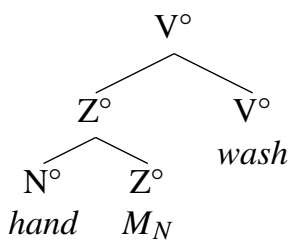


b. $\quad \lambda y_{e} \lambda e_{s} \lambda w_{w} \cdot \operatorname{wash}(y)(e)(w) \& \exists x[\operatorname{hand}(x)(w) \& \operatorname{RoLE}(x)(e)(w)]$

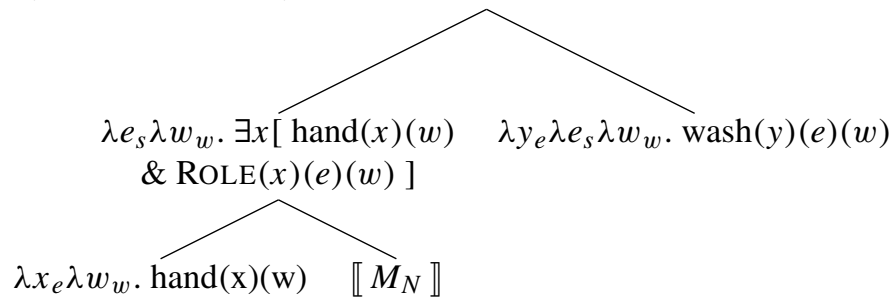

Thematic roles are freely selected, subject to the same pragmatic, syntactic, and semantic constraints that block implausible thematic roles and that completely rule out roles like agent or benefactive.

*We paper-wrote all weekend. (= we wrote a paper all weekend)
a. Agent:
* Someone will teacher-deliver the course.
b. Benefactive: *They will child-build the playset tomorrow.
c. Recipient: *Pratchett child-gave his books.
d. Comitative: *The bartender waiter-served the customers.

English, like Kiowa, allows certain systematic exceptions to the bar on object incorporation. When a categorizing head is added, it can bring with it a mediating relation that semantically licenses noun incorporation. Name-worthy activities license object incorporation, either at a cultural level or a subcultural level. Backformation only occurs when this kind of name-worthiness holds.
a. We deer hunt every year.
b. Pratchett world-builds like no other. (builds a world in sci-fi/fantasy).
c. Bilingual speakers code-switch regularly.

Another set of derivations license object incorporation: Synthetic compounds involve a noun+verb-affix structure. These routinely allow object incorporation, causing a long-standing syntactic paradox-possible forms built out of impossible ones.
a. truck driver, axe-wielding, data-driven
b. *truck-drive, *axe-wield, ??data-drive

Synthetic compounds have been thoroughly studied, so our semantic approach requires specific motivation. A substantial literature attempts to use this syntactic paradox to promote or dismiss derivational grammars, and to determine whether compounding is lexical or syntactic. With more recent theories of morphology (like Distributed Morphology), the second question has become less crucial. But the first question remains: How can the syntax build a structure out of one that cannot be built? Solutions simply allow the syntax to build the noun-verb stem, but another module of the grammar prevents its expression or spell-out.

Harley (2011) demonstrates how treating synthetic compounds like noun incorporation works well. The syntax allows head-movement of the nominalized root to become the sister of the verbal root, and end up linearized before it. 


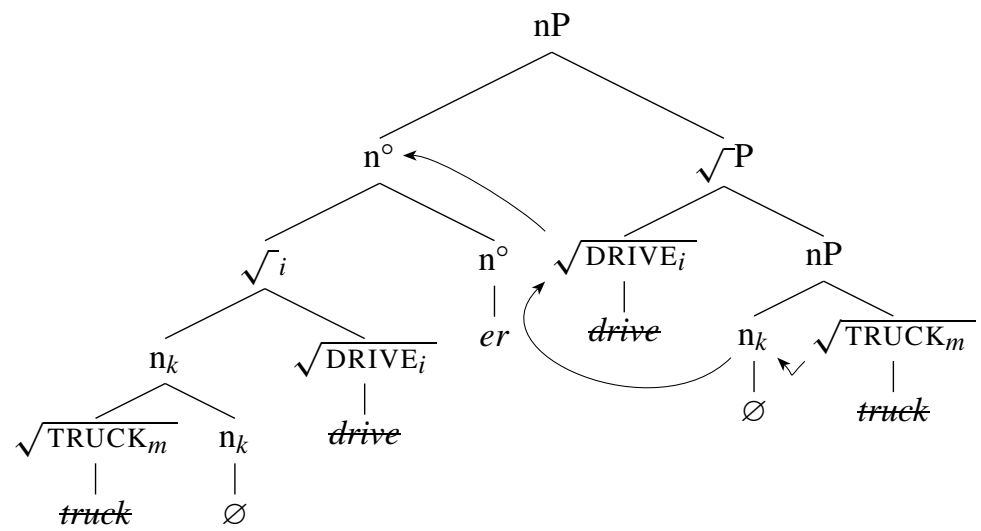

Under her account, a noun-incorporating verb like *truck-drive is barred by a prosodic constraint that prevents a verbalizing head $\left(\mathrm{v}^{\circ}\right)$ from hosting internallycomplex heads hosting more than one root, the way that nominalizing heads $\left(\mathrm{n}^{\circ}\right)$ can. However, this constraint is too strong. While it blocks the noun-incorporating verbs that do not occur, it also blocks many verbs that do occur. We bring up three such kinds of verbs.

First, McIntyre (2014) points out that English speakers routinely zero-derive verbs that contain multiple roots, and which are not backformed.

\section{grandstand, highlight, bear-hug}

Second, we have seen that English verbs can contain incorporated objects, if they fit Mithun's (1984) observation that 'name-worthy' descriptions can be lexicalized and allow incorporation (77). Third, as we have also seen, English verbs routinely incorporate noun roots, as long as the entities described by the noun are not the object of the verb.

Given these exceptions, we conclude that if there is a constraint, it applies to the inability to build noun-incorporating verbs, rather than to the ability. Nounincorporating verbs are perfectly grammatical to use if the noun is not the object, if the compound verb is lexicalized, or if the verb is embedded under an affix that creates a synthetic compound. As the first two are licensed by the presence of a mediating relation, so is the third: The categorizing affix introduces the relation.

The second method of building incorporated forms in Kiowa is to employ a categorizing head. Synthetic compounds employ such a projection, and in their case, the morpheme is overt. We give such a structure in (81). Again, we assume a basegeneration account. The noun and verb are sisters that compose semantically by Restrict, and the mediating relation on this categorizing head $\left(M_{V}\right)$ is interpreted above the noun+verb at LF and below the nominalizing head $\mathrm{N}_{b}{ }^{\circ}$.

\section{LF of truck driver, denotation of truck drive}


a.

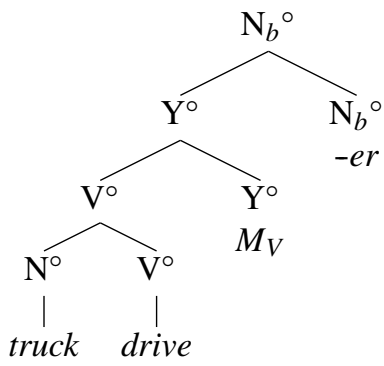

b.

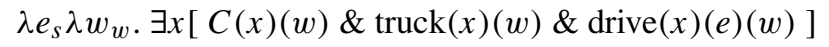

(via Restrict)
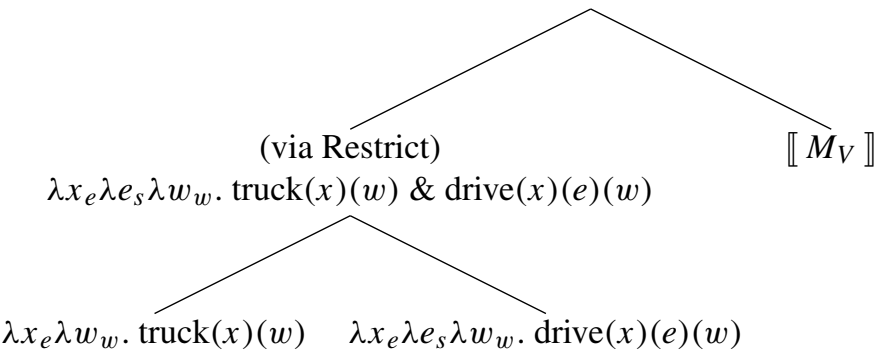

The meaning of truck drive is then applied to the agent nominal -er, whose meaning is somewhat complex and variable. For instance, the word keeper can describe a person who keeps/guards, or an item or person worth keeping. ${ }^{12}$ And even with truck driver, sometimes we are describing someone who drove a truck in a particular real-world situation, and other times the truck driver has yet to drive any trucks at all, but doing so is their job or role. We will set aside the difficulties in the meaning of -er, because they are not linked to the presence or absence of mediating relations. For now, we choose the 'job description' meaning of truck driver to demonstrate how it is derived with a mediating relation. The -er suffix takes a property of events and returns a property of nouns (82). The property of events already quantifies over the noun's entity argument, resulting in the observed meaning: In all worlds where $\mathrm{x}$ does $\mathrm{x}$ 's job, there is an event of $\mathrm{x}$ driving a truck.

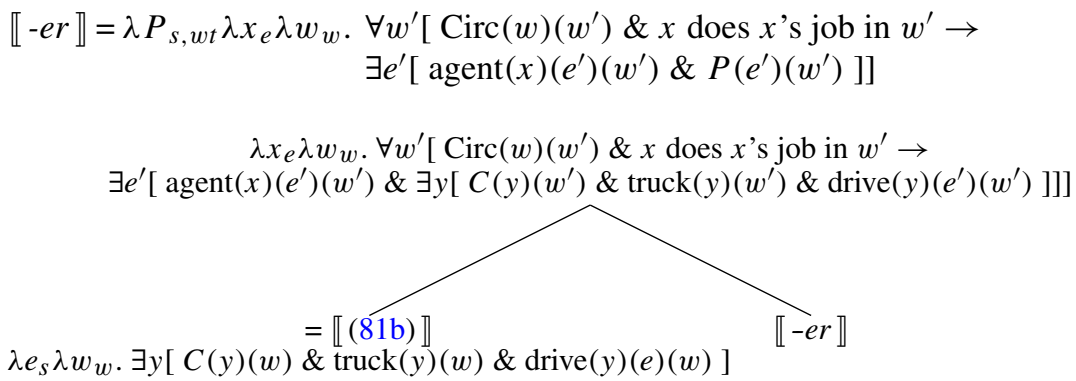

The existential quantifier can be interpreted with a narrow enough domain to trigger a sense of uniqueness in incorporated nouns. This effect is most noticeable when

\footnotetext{
${ }^{12}$ This discussion only involves $-e r$, but the analysis applies to other affixes that build synthetic compounds. They may differ in the relation their lexical item adds, but they employ the same mediating relation to bind nominal arguments and thus allow object incorporation.
} 
proper names are incorporated, like Obama-lover or Kardashian-following. If one is talking about a specific Obama, say Barack, the domain is narrow (e.g. the set of presidents). If one is talking about Obamas in general, like the family, then the domain is somewhat wider.

English employs two distinct mechanisms for incorporating nouns, so we should see if they can co-occur, and they can. Although, as was the case in Kiowa, it is quite difficult to construct them: The customer pimp-slapper is the person who slapped a customer like a pimp, but it still requires a bit of work to understand it. It is not clear why it should be difficult beyond processing. Perhaps the grammar plays a role in generally restricting noun incorporation to one noun in these languages, which if the case would raise interesting questions about the structure of these phenomena that future research can address.

Consequently, English incorporation and Kiowa incorporation work in very similar ways. They involve the same two mechanisms for building noun incorporating structures. Non-object incorporation and compound verb creation involves the alternate numeration of thematic information in a mediating relation between $\mathrm{N}^{\circ}$ and $\mathrm{V}^{\circ}$. The speaker can choose the the thematic role freely, subject to independent constraints. Object incorporation is generally barred, because there needs to be a mediating relation above the $\mathrm{N}^{\circ}+\mathrm{V}^{\circ}$ complex. However, if a categorizing head is present, it licenses such a relation. This relation does not introduce a thematic role, but does existentially quantify over the noun.

\section{Intransitive object incorporation}

In this paper we have laid out two mechanisms for noun incorporation: Alternative numeration of a thematic head into a mediating relation, and a categorization-driven mediating relation. The former works for non-objects, and the latter for objects. However, a well-observed distinction divides object-incorporation languages into those where the resulting verb is transitive (84), and those where it is intransitive (85).

(84) Transitive object NI: Southern Tiwa

A-diru+k'ar-hi.

$2 \mathrm{~S}>3 \mathrm{~S}-$ chicken+eat-FUT

'You will eat the chicken.'

(Allen et al. 1984:296)

(85) Intransitive object NI: West Greenlandic

Suluut timmisartu+liur-puq.

S.ABS airplane+make-IND:INTR:3S

'Suulut made an airplane.'

(Van Geenhoven 1998:99)

Earlier, we ruled out agent incorporation by pointing out that the agentive $v^{\circ}$ 's thematic role cannot be alternatively numerated and placed below $\mathrm{V}^{\circ}$, because that role is purely featural and the head's removal would have unwelcome consequences. However, it should be possible for a language to be able to employ a different $v^{\circ}$ head if it calls for an agent argument but does not assign case or license a full DP object. Such a head would have the effect of detransitivizing the verb, and this kind of noun incorporation is actually common. In many languages, object incorporation correlates with a reduction in the valence of the verb. 
(86) Chukchi

a. ənan qaa-t qərir-ninet

he.ERG deer-ABS.PL seek-3S $>3 P$

'He looked for the reindeer(pl),'

(Spencer 1995:444)

b. ətlon qaa+rer-ge?

he.ABS deer+seek-3s

(87) Yucatec Mayan

č'ak+če'-n-ah-en

chop+tree-ANTIP-PFV-1ABS

'I wood-chopped.'

(Mithun 1984:857)

In some languages, this structure is called the 'antipassive.' Although that term is difficult to define with certainty (Polinsky 2017), we can use it to describe valencereduction that removes objects from the argument structure rather than agents. The antipassive and incorporation have long been linked-Baker (1988) proposes that the 'antipassive' morpheme is merely a special case of NI by head movement. Rosen (1989) argues that detransitivized NI structures are compound verbs built in the lexicon. However, under the notion that external arguments are arguments of functional heads rather than verbs, we can shift any lexical difference to $v^{\circ}$. Assume that an antipassive $v^{\circ}$ ANTIP head has the same semantics as agentive $v^{\circ}$, but not its case feature. The antipassive does not cause the incorporation but is compatible with it. It does not interfere with the object incorporation, and the object incorporation does not interfere with the antipassive.

$$
(\simeq(86 b))
$$

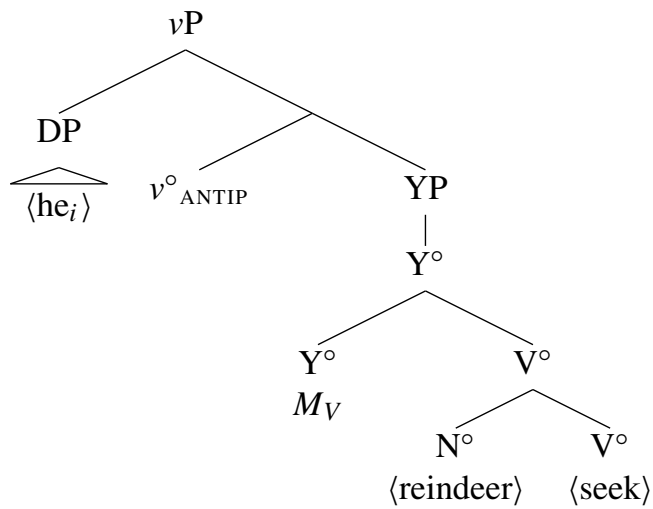

In contrast, passive detransitivization is not compatible with object incorporation. We use 'passive' to broadly describe cases where the agent is removed from the argument structure. Kiowa verbs have a detransitive form (89) that expresses several different non-agentive meanings (Watkins 1984, see (46)). This process does not license incorporation, though, and this account predicts why: The $v^{\circ}$ head does not introduce an agent argument. The theme is the subject and highest argument.

(89) a. Sân à-dàu é-kút. child stick-INV 3S > 3I-yank out.PFV

'The child yanked the stick out.' 

b. Ádàu è-kút-cá.
stick-INV 3I-yank out-DETR.PFV
'The stick popped out.' 'The stick was pulled out.'
c. *Ádàu é-kút-cá. stick-INV 3S $>3$ I-yank out-DETR.PFV (note the transitive agreement form)

Non-controlling agents can be added to detransitives, but with an applicative, leaving the theme the highest argument. This agent cannot be incorporated, nor can the object, which needs to be promoted out of the VP to be visible to nominative case.
a. Sân ádàu áu-kút-cá.
child stick-INV 3I:3sD-yank out-DETR.PFV
'The stick popped out on the child', 'The child managed to yank the stick out,' 'The child's stick popped out', 'The stick was pulled out by the child.'
b. *Sân (Ø/áu)-ä+kùt-cà.
c. *Ầdàu (è/áu)-sân+kùt-cà.

We have argued that the mediating relation head $\mathrm{Y}^{\circ}$ is compatible with the antipassive, but that is a weak finding, considering that the languages in question require the antipassive with object incorporation. At first we might see this as evidence that $M_{V}$ is directly introduced by $v^{\circ}$ ANTIP. However, we need not propose that. If we examine the nature of licensing (and case assignment) with transitive object-incorporation, we can see how the same licensing process with intransitive object-incorporation blocks other types of $v^{\circ}$.

When transitive object incorporation occurs, the agentive $v^{\circ}$ assigns case, and the nominal triggers agreement features. But what does $v^{\circ}$ assign case to? The incorporated noun lacks functional material needed for receiving case.

$$
\begin{aligned}
& \text { Bé-chát+hếdè! } \\
& 2 \mathrm{~S}>3 \text { I-entrance } \\
& \mathbf{C}
\end{aligned}
$$

'Open the door/tipi flap!'

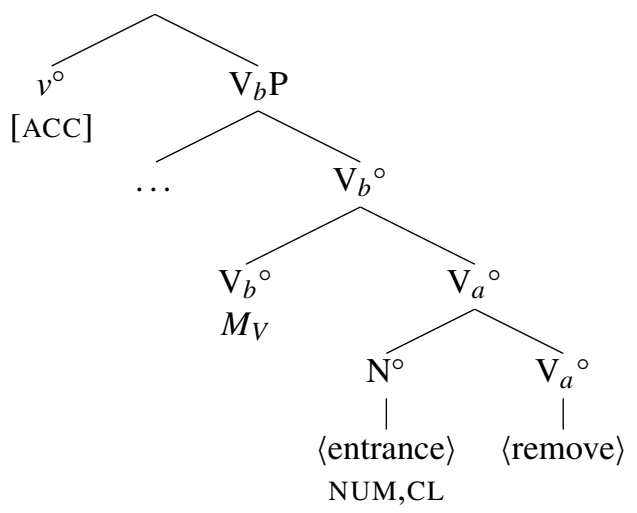


The noun does bear number and noun-class features that lead to the triggering of inverse agreement, however it lacks the determiner that hosts the inverse morpheme (Harbour 2007). ${ }^{13}$ And recall that in the semantics, the lack of a determiner, leaves the noun's entity argument unbound. The mediating relation solves that semantic problem, and we now propose that it also solves the licensing problem by being assigned the case value. The head that introduces the mediating relation bears a [D] feature (as it does quantify over entities), and it acquires number and class features of the noun, making them visible to verbal agreement. When $v^{\circ}$ is merged, it assigns its case to the mediating head's projection.

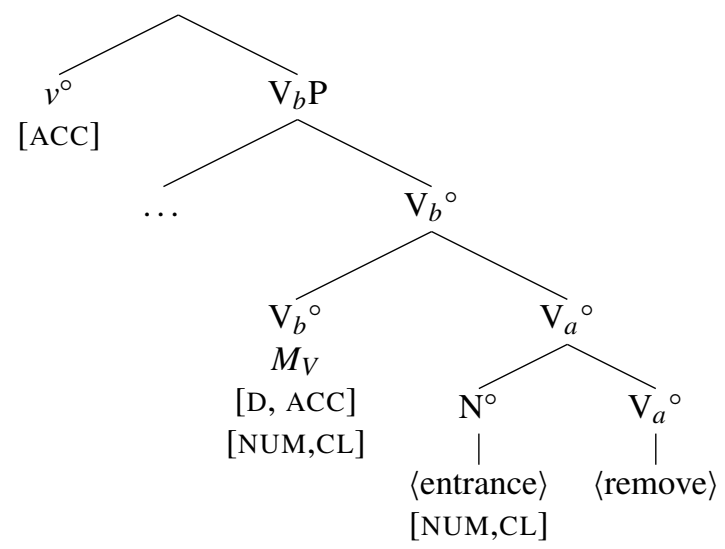

If case can be assigned to a categorizing head, the link between incorporation and antipassive can be reduced to whether that head can accept case. If the categorizing head bears a [D] feature permitting it to take case and trigger agreement, object incorporation is transitive. If it cannot, object incorporation would violate the case filter under a case-assigning $v^{\circ}$. The only other option is a $v^{\circ}$ that neither assigns case nor promotes the theme; that is, the antipassive.

\section{Conclusion}

The key question in this paper is how to resolve weak compositionality of thematic information in noun incorporation. We propose that noun incorporation requires a mediating relation to link the noun's semantics to that of the verb. One mediating relation $M_{N}$ takes nominal complements, quantifies over them, and assigns them a thematic role chosen by the speaker. The other mediating relation $M_{V}$ takes a verbal complement and quantifies over its entity argument. We show how the presence of mediating relations fills in the compositional gaps with incorporation of both objects and non-objects in Kiowa, and extend that account to English complex verbs and synthetic compounds.

\footnotetext{
${ }^{13}$ Harbour adds class and number heads to nouns to host these features. Consequently, it is probable that what we are incorporating as 'noun' is actually a Num projection. We omit this distinction since it does not contribute to our discussion here, which merely requires the nominal to lack crucial determiner features.
} 
Each mediating relation reflects a distinct way of building noun incorporation structures in the syntax. $M_{N}$ involves the alternate numeration of thematic relations. Instead of drawing an adposition from the lexicon, speakers employ this mediating relation between the noun and the verb. Speakers using $M_{N}$ are free to choose any thematic role, except for those linked to functional heads in the extended verbal projection, and except for theme roles, which are assigned directly by the verb.

Object incorporation results from re-categorization of the verb with a head bearing $M_{V}$. This head assigns no thematic role, but merely quantifies over the object. In some languages, like Kiowa, this head can bear nominal features like [D], case, and agreement, so object incorporation does not affect argument structure. In other languages, like West Greenlandic, this head cannot bear these features, so object incorporation requires detransitivizing the verb. Since an agent is still required, the antipassive results.

This paper thus offers semantic evidence toward the notion that there are multiple ways to build noun incorporation structures (Johns 2007; Massam 2009; Baker 2009; Barrie 2015). It is likely that there are multiple ways to build pseudo-incorporation structures as well (Farkas and de Swart 2003; Dayal 2011, 2015). It still remains to be determined why these mediating relations do not trigger overt morphology crosslinguistically, unless one counts the incorporation itself. We also have yet to determine why the object incorporation head is productive outside of lexicalized contests in some languages yet not in others. Nonetheless, we have made significant progress in understanding what to look for, due to a clearer understanding of what incorporation means, and we have gained a sense of how incorporation structures depend on the interaction of multiple modules of the grammar.

Acknowledgements The author would like to thank first and foremost the Kiowa elders who have graciously and patiently shared their knowledge: Dorothy Whitehorse Delaune, Delores Harragarra, Juanita Ahtone. Portions and precursors of this work have been presented to audiences at the University of Kansas and the University of Arizona, and at WCCFL 36; the commentary and feedback from those audiences have been very helpful.

Funding information This work was funded by a grant (\#BCS-1664431) under the Documenting Endangered Languages program, from the National Science Foundation and National Endowment for the Humanities (US). Early stages were funded by a New Faculty Research Grant from the University of Kansas.

Publisher's Note Springer Nature remains neutral with regard to jurisdictional claims in published maps and institutional affiliations.

Open Access This article is licensed under a Creative Commons Attribution 4.0 International License, which permits use, sharing, adaptation, distribution and reproduction in any medium or format, as long as you give appropriate credit to the original author(s) and the source, provide a link to the Creative Commons licence, and indicate if changes were made. The images or other third party material in this article are included in the article's Creative Commons licence, unless indicated otherwise in a credit line to the material. If material is not included in the article's Creative Commons licence and your intended use is not permitted by statutory regulation or exceeds the permitted use, you will need to obtain permission directly from the copyright holder. To view a copy of this licence, visit http://creativecommons.org/licenses/by/ $4.0 \%$. 


\section{References}

Adger, David, Daniel Harbour, and Laurel Watkins. 2009. Mirrors and Microparameters: Phrase structure beyond free word order. Cambridge: Cambridge Univ. Press.

Allen, Barbara J., Donna B. Gardiner, and Donald G. Frantz. 1984. Noun incorporation in Southern Tiwa. International Journal of American Linguistics 50(3): 292-311. https://doi.org/10.1086/465837.

Baker, Mark. 1988. Incorporation: A theory of grammatical function changing. Chicago: University of Chicago Press.

Baker, Mark. 1996. The polysynthesis parameter. Oxford: Oxford University Press.

Baker, Mark. 2009. Is head movement still needed for noun incorporation? Lingua 119(2): 148-165. https://doi.org/10.1016/j.lingua.2007.10.010.

Baker, Mark. 2014. Pseudo noun incorporation as covert noun incorporation: Linearization and crosslinguistic variation. Language and Linguistics 15(1): 5-46. https://doi.org/10.1177/ $1606822 X 13506154$.

Barrie, Michael. 2012. Noun incorporation and the lexicalist hypothesis. Studies in Generative Grammar 22: 235-261.

Barrie, Michael. 2015. Two kinds of structural noun incorporation. Studia Linguistica 69(3): 237-271. https://doi.org/10.1111/stul.12034.

Barrie, Michael, and Audrey Li. 2015. The semantics of (pseudo) incorporation and case. In The syntax and semantics of pseudo-incorporation, eds. Olga Borik and Berit Gehrke. Leiden: Brill. https:// doi.org/10.1163/9789004291089_006.

Barrie, Michael, and Éric Mathieu. 2012. Head movement and noun incorporation. Linguistic Inquiry 43(1): 133-142. https://doi.org/10.1162/ling_a_00077.

Barrie, Michael, and Éric Mathieu. 2016. Noun incorporation and phrasal movement. Natural Language \& Linguistic Theory 34(1): 1-51. https://doi.org/10.1007/s11049-015-9296-6.

Bauer, Laurie, and Antoinette Renouf. 2001. A corpus-based study of compounding in English. Journal of English Linguistics 29(2): 101-123. https://doi.org/10.1177/00754240122005251.

Carlson, Gregory N. 1977. Reference to kinds in English. PhD diss., University of Massachusetts Amherst. http://scholarworks.umass.edu/dissertations/AAI7726414. Last accessed 5 March 2021.

Chung, Sandra, and William A. Ladusaw. 2003. Restriction and saturation. Cambridge: MIT Press.

Chung, Sandra, and William A. Ladusaw. 2006. Chamorro evidence for compositional asymmetry. Natural Language Semantics 14(4): 325-357. https://doi.org/10.1007/s11050-007-9007-x.

Compton, Richard, and Christine Pittman. 2010. Word-formation by phase in Inuit. Lingua 129(9): 2167-2192. https://doi.org/10.1016/j.lingua.2010.03.012.

Dayal, Veneeta. 2011. Hindi pseudo-incorporation. Natural Language \& Linguistic Theory 29(1): 123-167. https://doi.org/10.1007/s11049-011-9118-4.

Dayal, Veneeta. 2015. Incorporation: Morpho-syntactic vs. semantic considerations. In The syntax and semantics of pseudo-incorporation, eds. Olga Borik and Gerit Behrke, 47-87. Leiden: Brill. https:// doi.org/10.1163/9789004291089_003.

Elbourne, Paul. 2005. Situations and individuals. Cambridge: MIT Press.

Farkas, Donka, and Henriëtte de Swart. 2003. The semantics of incorporation: From argument structure to discourse transparency. Chicago: University of Chicago Press.

Harbour, Daniel. 2007. Morphosemantic number: From Kiowa noun classes to UG number features. Dordrecht: Springer.

Harley, Heidi. 2011. Compounding in distributed morphology. Oxford: Oxford University Press. https:// doi.org/10.1093/oxfordhb/9780199695720.013.0007.

Harrington, John Peabody. 1928. Vocabulary of the Kiowa language, Vol. Bulletin 84. Washington, D.C.: Bureau of American Ethnology.

Heck, Fabian, and Marc Richards. 2010. A probe-goal approach to agreement and non-incorporation restrictions in Southern Tiwa. Natural Language and Linguistic Theory 28: 681-721. https:// doi.org/10.1007/s11049-010-9108-y.

Heim, Irene. 1982. The semantics of definite and indefinite noun phrases. PhD diss., University of Massachusetts Amherst.

Jackson, Scott, and Jeffrey Punske. 2013. Deriving English compound stress: Insights from Distributed Morphology and multiple spell-out. Linguistic Analysis 38(3): 243-274.

Johns, Alana. 2007. Restricting noun incorporation: Root movement. Natural Language \& Linguistic Theory 25(3): 535-576. https://doi.org/10.1007/s11049-007-9021-1.

Kracht, Ben. 2017. Kiowa belief and ritual. Lincoln: U of Nebraska Press. 
Kratzer, Angelika. 1996. Severing the external argument from its verb. In Phrase structure and the lexicon, eds. Johan Rooryck and Laurie Zaring, 109-137. Dordrecht: Kluwer.

Landau, Idan. 2015. A two-tiered theory of control. Cambridge: MIT Press.

Levin, Theodore. 2017. Distinguishing object agreement and clitic doubling in noun incorporation. In North East Linguistic Society (NELS) 47, eds. Andrew Lamont and Katerina Tetzloff, Vol. 2, 241-250. Amherst: GLSA.

Lieber, Rochelle. 1992. Deconstructing morphology. Chicago: University of Chicago Press.

Massam, Diane. 2009. Noun incorporation: Essentials and extensions. Language and Linguistics Compass 3(4): 1076-1096. https://doi.org/10.1111/j.1749-818x.2009.00140.x.

McIntyre, Andrew. 2014. Synthetic compounds and argument structure: Messages from a bandwagonjumper-onner and a two-cents-worth-thrower-inner. http://bit.ly/2hIrRle.

McKenzie, Parker P., and William C. Meadows. 2001. The Parker P. McKenzie Kiowa orthography: How written Kiowa came into being. Plains Anthropologist 46(177): 233-237. https://doi.org/10.1080/ 2052546.2001.11932030.

Mithun, Marianne. 1984. The evolution of noun incorporation. Language 60(4): 847-894. https://doi.org/ $10.2307 / 415599$.

Mithun, Marianne. 2004. The non-universality of obliques. Presented at Syntax of the World's Languages.

Mithun, Marianne. 2009. Polysynthesis in the Arctic. In Typological studies in language, 3-17. Amsterdam: John Benjamins. https://doi.org/10.1075/ts1.86.01pol.

Neely, Amber, and Gus Palmer, Jr.. 2009. Which way is the Kiowa way? Orthography choices, ideologies, and language renewal. In Native American language ideologies: Beliefs, practices, and struggles in Indian Country., eds. Paul V. Kroskrity and Margaret C. Field, 271-298. Tucson: University of Arizona Press.

Pirrelli, Vito. 2002. Per un superamento della dicotomia lessico-grammatica. Aspetti di composizionalità 'debole' nel linguaggio. In La lessicografia bilingue tra presente e avvenire, eds. Elena Ferrario and Virginia Pulcini, 187-203. Vercelli: Edizioni Mercurio.

Polinsky, Maria. 2017. Antipassive. In The Oxford handbook of ergativity, eds. Jessica Coon, Diane Massam, and Lisa Demena Travis. Oxford: Oxford U. Press. https://doi.org/10.1093/oxfordhb/ 9780198739371.013.13.

Redbird, Charlie. n.d. Wagon attack. Recorded by the Summer Institute of Linguistics.

Rosen, Sara Thomas. 1989. Two types of noun incorporation: A lexical analysis. Language 65(2): 294-317. https://doi.org/10.2307/415334.

Roy, Thomas Fredrick. 2007. Yí:sàum: Parker McKenzie's double vision of Kiowa culture and language. PhD diss., University of Oklahoma. https://hdl.handle.net/11244/1157. Last accessed 5 March 2021.

Sadock, Jerrold. 1980. Noun incorporation in Greenlandic: A case of syntactic word formation. Language 56(2): 300-319. https://doi.org/10.2307/413758.

Schwarz, Florian. 2014. How weak and how definite are weak definites? In Weak referentiality, ed. Ana Aguilar Guevara. Amsterdam: John Benjamins. https://doi.org/10.1075/la.219.09sch.

Spencer, Andrew. 1995. Incorporation in Chukchi. Language 71(3): 439-489. https://doi.org/10.2307/ 416217.

Toyebo, Lewis. n.d. Jonah and the whale. Recorded by the Summer Institute of Linguistics.

Van Geenhoven, Veerle. 1998. Semantic incorporation and indefinite descriptions. Stanford: CSLI.

Van Geenhoven, Veerle. 2002. Raised possessors and noun incorporation in West Greenlandic. Natural Language and Linguistic Theory 20(4): 759-821. https://doi.org/10.1023/A:1020481806619.

Van Geenhoven, Veerle, and Louise McNally. 2005. On the property analysis of opaque complements. Lingua 115(6): 885-914. https://doi.org/10.1016/j.lingua.2004.01.012.

Watkins, Laurel. 1984. A grammar of Kiowa. Lincoln: U of Nebraska Press.

Watkins, Laurel, and Daniel Harbour. 2010. The linguistic genius of Parker McKenzie's Kiowa alphabet. International Journal of American Linguistics 76(3): 309-333. https://doi.org/10.1086/652791.

Watkins, Laurel J. 1990. Noun phrase versus zero in Kiowa discourse. International Journal of American Linguistics 56(3): 410-426.

Zimmermann, Thomas Ede. 1993. On the proper treatment of opacity in certain verbs. Natural Language Semantics 1(2): 149-179. https://doi.org/10.1007/bf00372561. 